\title{
Hybrid inhibitor of peripheral cannabinoid-1 receptors and inducible nitric oxide synthase mitigates liver fibrosis
}

Resat Cinar, ${ }^{1}$ Malliga R. Iyer, ${ }^{1}$ Ziyi Liu, ${ }^{1}$ Zongxian Cao, ${ }^{2}$ Tony Jourdan, ${ }^{1}$ Katalin Erdelyi, ${ }^{2}$ Grzegorz Godlewski, ${ }^{1}$ Gergő Szanda, ${ }^{1}$ Jie Liu, ${ }^{1}$ Joshua K. Park, ${ }^{1}$ Bani Mukhopadhyay, ${ }^{1}$ Avi Z. Rosenberg, ${ }^{3,4}$ Jeih-San Liow, ${ }^{5}$ Robin G. Lorenz, ${ }^{6}$ Pal Pacher, ${ }^{2}$ Robert B. Innis, ${ }^{5}$ and George Kunos

'Laboratory of Physiologic Studies and 'Laboratory of Oxidative Stress and Tissue Injury, National Institute on Alcohol Abuse and Alcoholism, Washington, DC, USA. ${ }^{3}$ Kidney Diseases Section, National Institute on Diabetes, Digestive, and Kidney Diseases, Washington, DC, USA. ${ }^{4}$ Children's National Medical Center, Washington, DC, USA. ${ }^{5}$ Molecular Imaging Branch, National Institute on Mental Health, NIH, Bethesda, Maryland, USA. ${ }^{6}$ Department of Pathology, University of Alabama at Birmingham, Birmingham, Alabama, USA.

Liver fibrosis, a consequence of chronic liver injury and a way station to cirrhosis and hepatocellular carcinoma, lacks effective treatment. Endocannabinoids acting via cannabinoid-1 receptors $\left(C_{1} R\right)$ induce profibrotic gene expression and promote pathologies that predispose to liver fibrosis. $\mathrm{CB}_{1} \mathrm{R}$ antagonists produce opposite effects, but their therapeutic development was halted due to neuropsychiatric side effects. Inducible nitric oxide synthase (iNOS) also promotes liver fibrosis and its underlying pathologies, but iNOS inhibitors tested to date showed limited therapeutic efficacy in inflammatory diseases. Here, we introduce a peripherally restricted, orally bioavailable $\mathrm{CB}_{1} \mathrm{R}$ antagonist, which accumulates in liver to release an iNOS inhibitory leaving group. In mouse models of fibrosis induced by $\mathrm{CCl}_{4}$ or bile duct ligation, the hybrid $\mathrm{CB}_{1} \mathrm{R} / \mathrm{iNOS}$ antagonist surpassed the antifibrotic efficacy of the $\mathrm{CB}_{1} \mathrm{R}$ antagonist rimonabant or the iNOS inhibitor $1400 \mathrm{~W}$, without inducing anxiety-like behaviors or $\mathrm{CB}_{1} \mathrm{R}$ occupancy in the CNS. The hybrid inhibitor also targeted $\mathrm{CB}_{1} \mathrm{R}$-independent, iNOS-mediated profibrotic pathways, including increased PDCF, NIrp3/Asc3, and integrin $\alpha \mathrm{v} \beta 6$ signaling, as judged by its ability to inhibit these pathways in $\mathrm{cnr}^{-/-}$but not in nos2 ${ }^{-/-}$mice. Additionally, it was able to slow fibrosis progression and to attenuate established fibrosis. Thus, dual-target peripheral $\mathrm{CB}_{1} \mathrm{R} / \mathrm{iNOS}$ antagonists have therapeutic potential in liver fibrosis.

Authorship note: R. Cinar and M.R. Iyer contributed equally to this work.

Conflict of interest: R. Cinar, M.R. Iyer, and $\mathrm{G}$. Kunos are listed as coinventors on a US patent application covering MRI1867 and related compounds (patent no. 2.PCT/US2013/069686).

Submitted: March 1, 2016 Accepted: June 17, 2016 Published: July 21, 2016

Reference information: JCI Insight. 2016;1(11):e87336. doi:10.1172/jci.insight.87336.

\section{Introduction}

Fibrosis results from excessive extracellular matrix deposition that accompanies chronic inflammation or wound healing and is a key pathogenic process in many organs, including the liver. Liver fibrosis is a consequence of chronic liver injury associated with alcoholic or nonalcoholic fatty liver disease, viral hepatitis, or metabolic diseases (1). Although the pathogenesis of fibrosis has common features across different organs, the exact mechanisms involved are not fully understood. Unfortunately, there is no effective antifibrotic therapy approved for human use; therefore, there is an urgent need for identifying novel treatment modalities.

For multifactorial chronic diseases, such as fibrosis, the conventional pharmacological approach based on the "one-disease/one-target/one-drug" paradigm limits therapeutic efficacy and could be improved by simultaneously hitting multiple therapeutic targets (2). Although this could be achieved by combination therapy, there are drawbacks to using multiple chemical entities, such as differences in pharmacokinetics and target organ engagement, and a wider range of drug-drug interactions and adverse effects. These issues could be mitigated by developing a single drug that has more than one therapeutic target. When applied to liver fibrosis, such an approach could aim at both preventing its progression and reversing the process, leading to improved liver function (3). This could best be achieved by engaging targets involved not only in 
A

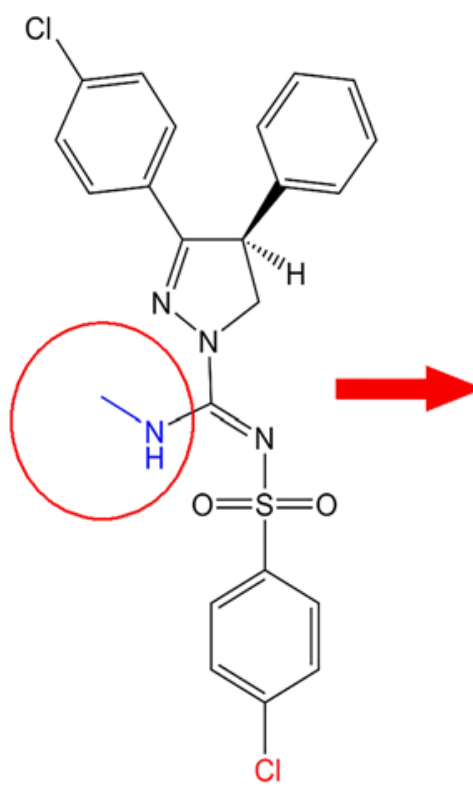

SLV319

(Ibipinabant)
B

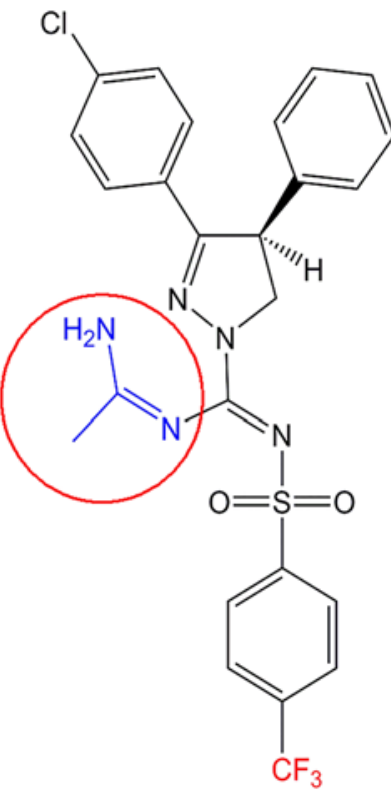

(-)-MRI-1867

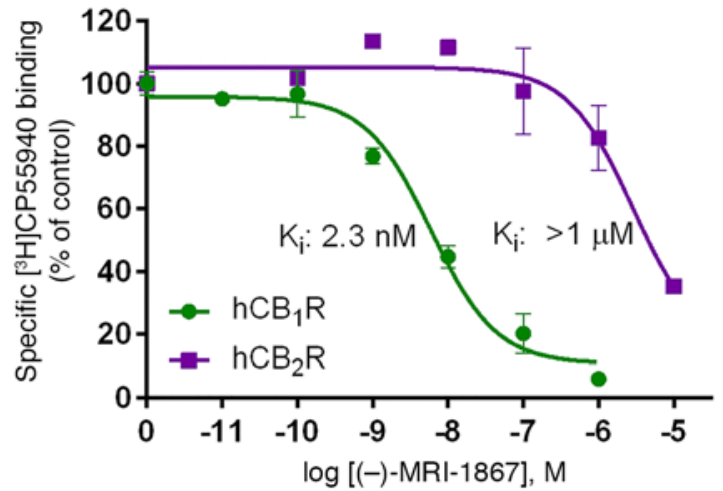

Figure 1. Chemical structure and $C_{1} R_{1}$ affinity and selectivity of a hybrid $C_{1} R / i N O S$ inhibitor. (A) Design and chemical structure of the $C B_{1} R$-active enantiomer (-)-MRI-1867. (B) $\mathrm{CB}_{1} \mathrm{R}$-binding affinity and $\mathrm{CB}_{1} \mathrm{R} / \mathrm{CB}_{2} \mathrm{R}$ selectivity of (-)-MRI-1867. Binding affinity was determined by computer-assisted analysis of binding displacement isotherms using $1 \mathrm{nM}$ or $0.6 \mathrm{nM}$ of $\left[{ }^{1} \mathrm{H}\right]-\mathrm{CP}_{2} 5940$ as the labeled ligand and plasma membranes from $\mathrm{CB}_{1} \mathrm{R}$ - or $\mathrm{CB}_{2} \mathrm{R}$-expressing $\mathrm{CHO}-\mathrm{K} 1$ cells, respectively. $\mathrm{K}_{\mathrm{i}}$ values were calculated using the Cheng-Prusoff equation. Data represent mean \pm SEM from 3 independent experiments performed in triplicates.

the fibrotic process itself, but also in the underlying pathologic conditions that predispose to liver fibrosis, as described above.

One such target is the endocannabinoid/cannabinoid-1 receptor (endocannabinoid/CB $\mathrm{R}$ ) system. Endocannabinoids are lipid signaling molecules that act on the same cannabinoid receptors $-\mathrm{CB}_{1}$ and $\mathrm{CB}_{2}$ - that mediate the effects of marijuana (4). An overactive endocannabinoid $/ \mathrm{CB}_{1} \mathrm{R}$ system contributes to visceral obesity and its complications (5), including type 2 diabetes (6), and also plays a role in the pathology of alcoholic fatty liver disease (7) and viral hepatitis (8). Conversely, $\mathrm{CB}_{1} \mathrm{R}$ blockade has beneficial effects in preclinical models of these conditions $(7,9)$ as well as in overweight individuals with metabolic syndrome (10). Endocannabinoids acting via $\mathrm{CB}_{1} \mathrm{R}$ have also been implicated in liver fibrosis in the absence of obesity, and the prototype $\mathrm{CB}_{1} \mathrm{R}$ inverse agonist rimonabant has moderate antifibrotic efficacy in animal models (11). However, rimonabant and related brain-penetrant $C_{1} R$ antagonists cause psychiatric side effects due to blockade of $\mathrm{CB}_{1} \mathrm{R}$ in the $\mathrm{CNS}$, which halted their therapeutic development. Non-brain-penetrant $\mathrm{CB}_{1} \mathrm{R}$ antagonists have recently been reported to retain the metabolic benefit of globally acting compounds $(6,12,13)$, but their therapeutic potential in liver fibrosis has not yet been evaluated.

Another potential therapeutic target involved in both fibrosis and its underlying pathologies is inducible nitric oxide synthase (iNOS), an enzyme that catalyzes the generation of proinflammatory reactive nitrogen species. iNOS-producing hepatic macrophages have been identified as the main fibrogenic cell population in experimental liver fibrosis (14), which can be attenuated by genetic deletion (15) or pharmacologic inhibition of iNOS (16). Furthermore, increased iNOS activity contributes to alcoholic liver disease (17) and the progression of viral hepatitis (18) and is also involved in diet-induced steatohepatitis (19), insulin resistance (20), and obesity-associated inflammation and endoplasmic reticulum dysfunction (21). Thus, iNOS is another promising therapeutic target for liver fibrosis. However, first-generation iNOS inhibitors lacked oral bioavailability (16), whereas more recently developed, orally bioavailable iNOS inhibitors have had disappointingly low therapeutic efficacy in clinical trials involving inflammatory diseases (22).

Here, we introduce a peripherally restricted $\mathrm{CB}_{1} \mathrm{R}$ inverse agonist, which accumulates in the liver to release a metabolically cleaved leaving group with potent iNOS inhibitory activity, resulting in high expo- 
A

Acute

$3 \mathrm{mg} / \mathrm{kg}$

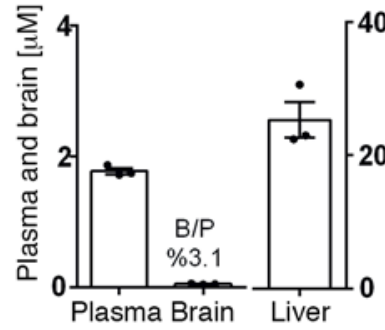

Free conc.

in brain $(\mathrm{nM})$

B

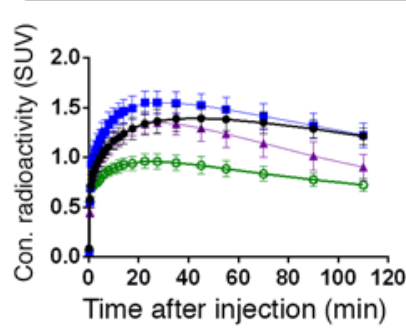

V

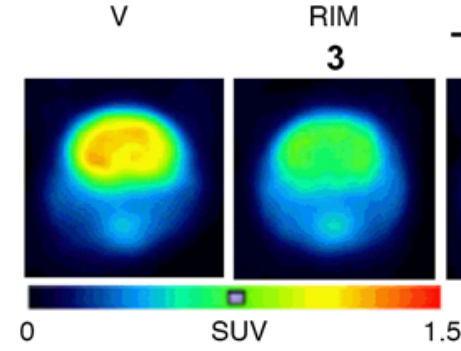

C

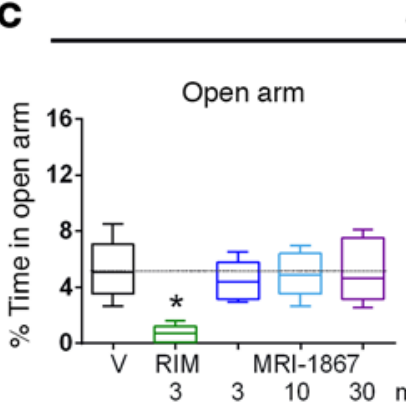

Acute
Acute

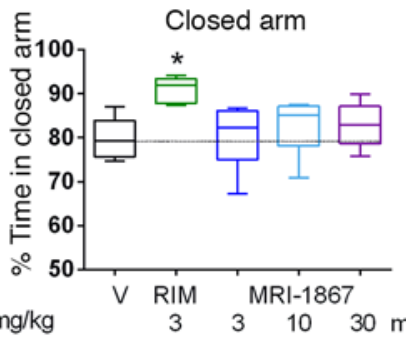

$30 \mathrm{mg} / \mathrm{kg}$

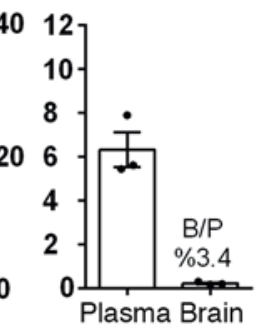

0.9
Chronic

$3 \mathrm{mg} / \mathrm{kg}$
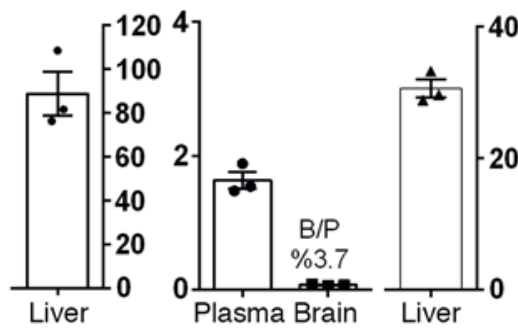

0.3
$30 \mathrm{mg} / \mathrm{kg}$

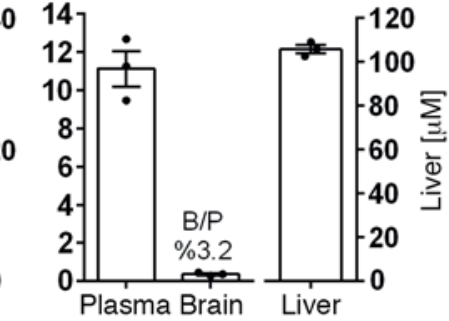

1.2
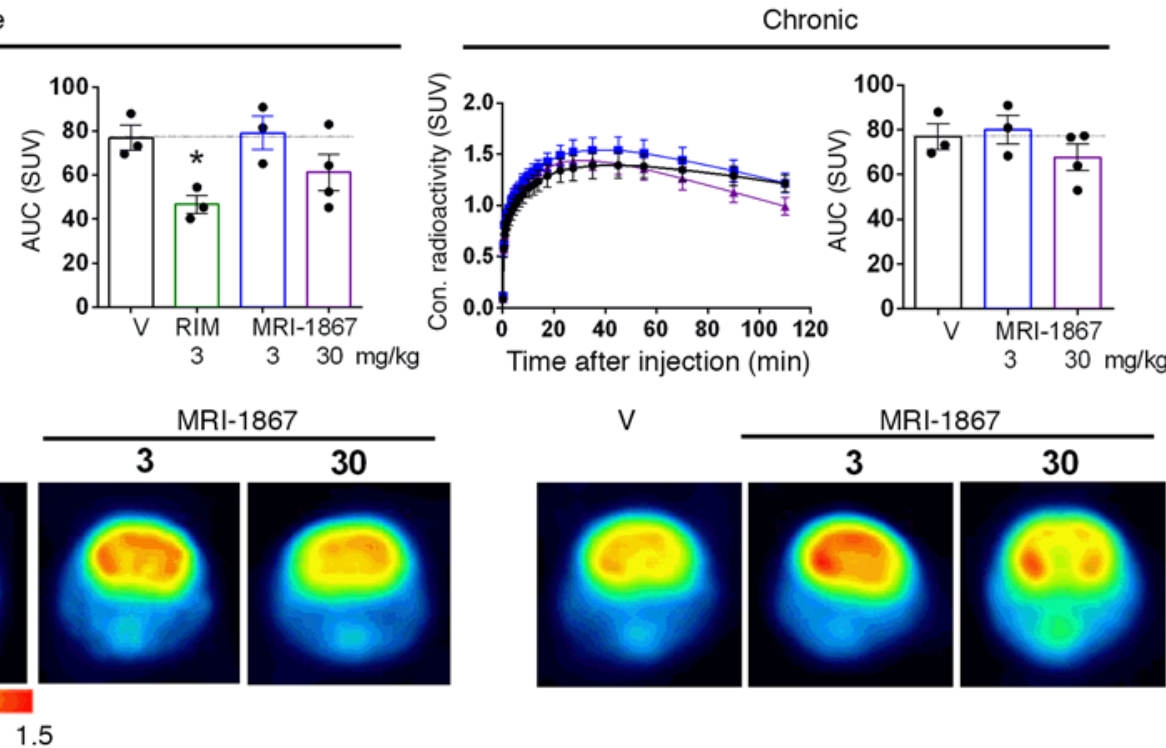

Chronic

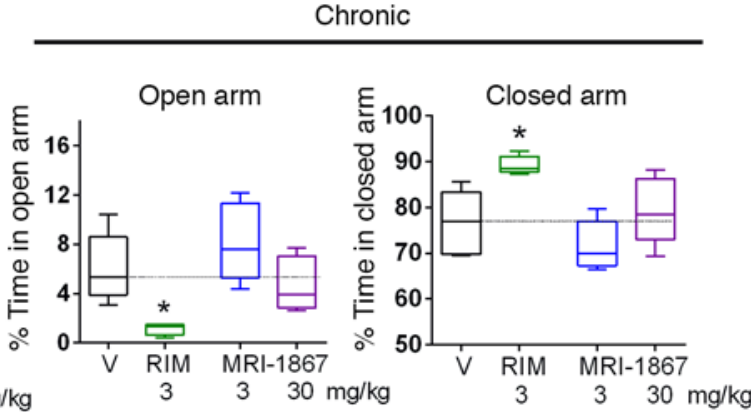

Figure 2. Peripheral selectivity of MRI-1867. (A) Tissue distribution of MRI-1867, as determined by LC-MS/MS 1 hour after acute or 28-day chronic oral dosing at 3 and $30 \mathrm{mg} / \mathrm{kg}$. Numbers below graphs indicate concentrations in nM of unbound MRI-1867 in brain, determined by equilibrium dialysis using brain membranes from $\mathrm{CB}_{1} \mathrm{R}^{-/-}$mice. (B) Brain $\mathrm{CB}_{1} \mathrm{R}$ occupancy by MRI-1867 or rimonabant, as determined by $\mathrm{CB}_{1} \mathrm{R}$ PET following acute or chronic treatment with the indicated doses. Data in $\mathbf{A}$ and $\mathbf{B}$ represent mean \pm SEM from 3-4 mice/group. Data from the same 3 vehicle-treated mice were used as controls for both the acute and chronic pretreatment groups, and the same representative CB $R$ PET image from a vehicle-treated mouse is shown for both the acute and chronic pretreatment groups. (C) Rimonabant ( $3 \mathrm{mg} / \mathrm{kg}$ ), but not MRI-1867 (3-30 mg/kg), is anxiogenic in the elevated plus maze test ( $n=6$ [vehicle], $n=5$ [rimonabant], and $n=6$ [MRI-1867] mice/group). Data in B and C were analyzed by 1-way ANOVA followed by Dunnett's multiple comparisons test, ${ }^{*} P<0.05$ relative to vehicle.

sure of both targets in the liver without detectable exposure of $\mathrm{CB}_{1} \mathrm{R}$ in the brain. In two mouse models of liver fibrosis, the antifibrotic efficacy of the hybrid compound exceeds that of rimonabant due to inhibition of profibrotic pathways uniquely engaged by iNOS, as verified through the use of mice deficient either in $\mathrm{CB}_{1} \mathrm{R}$ or iNOS, and is able not only to slow fibrosis progression, but also to attenuate established fibrosis. 


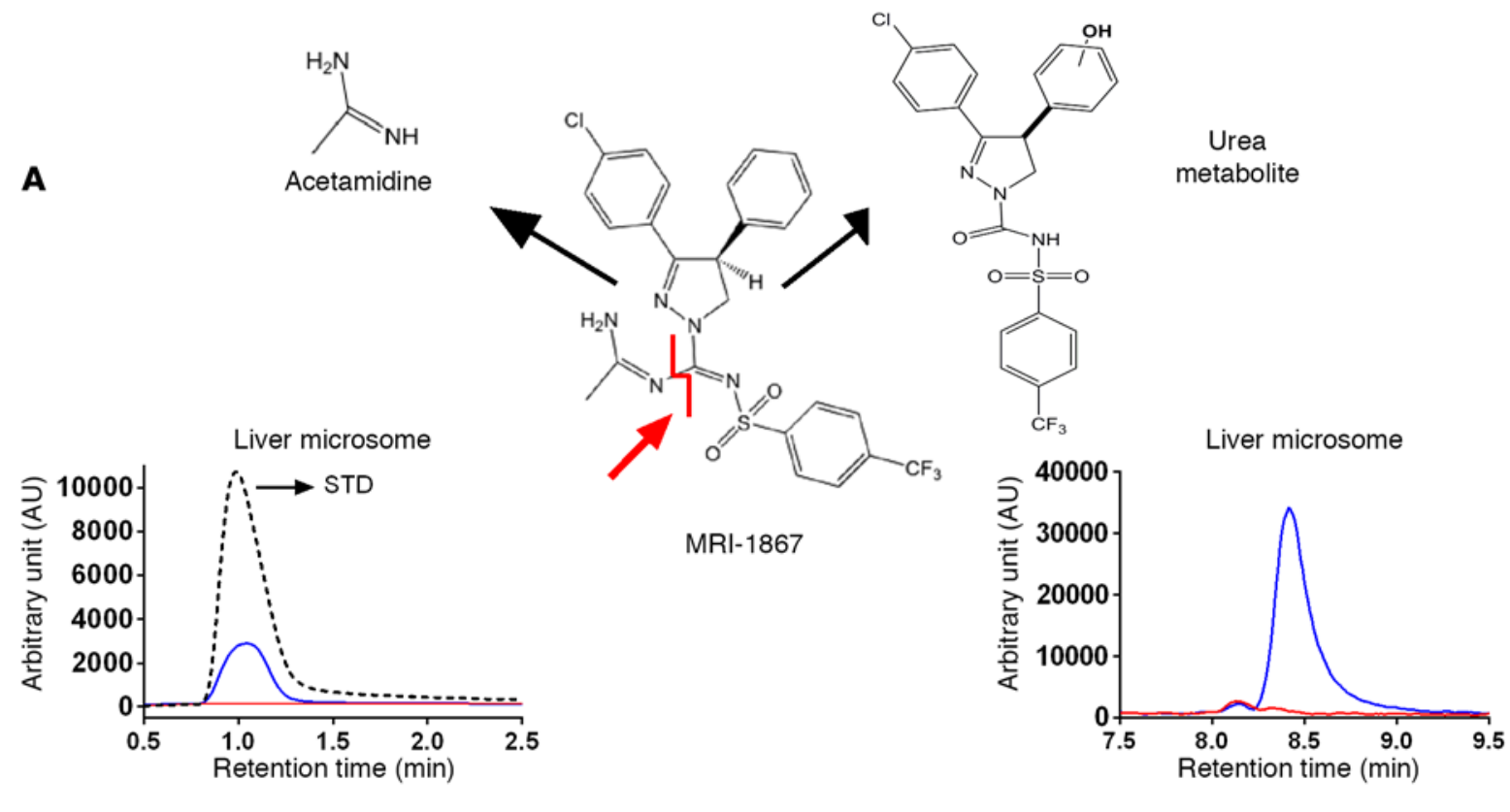

B

iNOS activity in raw 264.7 cells

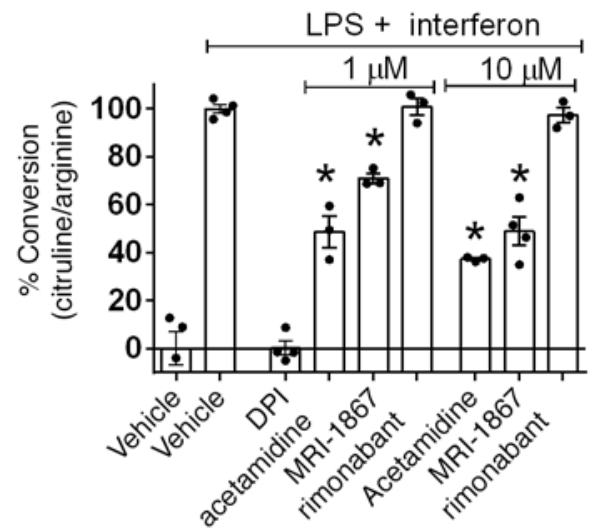

C

eNOS activity

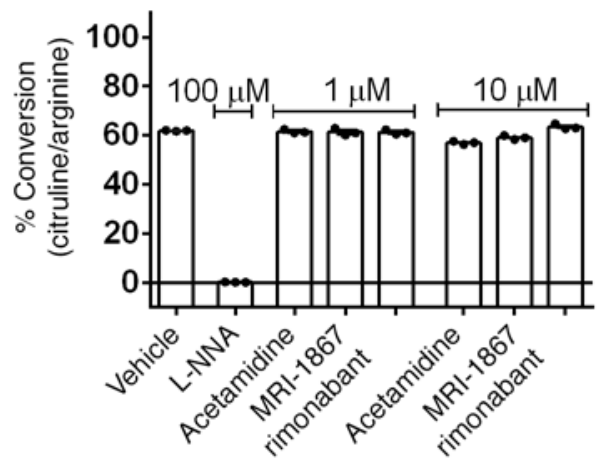

Figure 3. Inhibition of iNOS by a hybrid CB,R/iNOS antagonist. (A) Metabolism of MRI-1867 by liver microsomes yields acetamidine and a urea metabolite. (B) Effects of MRI-1867, acetamidine, rimonabant, and positive control diphenylene iodonium (DPI, iNOS inhibitor, 1 mM) on iNOS activity in RAW 264.7 cells preincubated with LPS $(50 \mathrm{ng} / \mathrm{ml})$ plus $\gamma$-interferon $(10 \mathrm{ng} / \mathrm{ml})$ for 24 hours. (C) Lack of effect of MRI-1867, rimonabant, or acet-

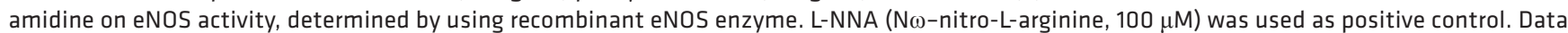
in $\mathbf{B}$ and $\mathbf{C}$ were analyzed by 1-way ANOVA followed by Dunnett's multiple comparisons test, ${ }^{*} P<0.05$ indicates significant inhibition of iNOS relative to LPS- or LPS $+\gamma$-interferon-treated control.

\section{Results}

Design and pharmacological properties of a dual $C B_{I} R /$ iNOS inhibitor. In order to optimize the antifibrotic therapeutic potential of $\mathrm{CB}_{1} \mathrm{R}$ blockade, we have modified the structure of the brain-penetrant $\mathrm{CB}_{1} \mathrm{R}$ antagonist/inverse agonist ibipinabant (23) to generate compounds with limited brain penetrance while retaining high potency and selectivity as $\mathrm{CB}_{1} \mathrm{R}$ antagonist and also acting as parent drug or pro-drug to directly inhibit iNOS activity.

The design of peripherally restricted hybrid $\mathrm{CB}_{1} \mathrm{R} / \mathrm{iNOS}$ inhibitors involved chemically attaching an acetamidine moiety, known for its iNOS inhibitory activity (24), to the core chemical scaffold (see the Methods, Figure 1, and Supplemental Figures 1 and 2; supplemental material available online with this article; doi:10.1172/jci.insight.87336DS1). Acetamidine is a polar chemical moiety with limited ability to penetrate biological membranes, so its chemical attachment to the apolar sulfonylurea scaffold would increase the polar surface area of the hybrid structure, limiting its brain penetrance. Furthermore, the hybrid compound could serve as a pro-drug and a carrier for the iNOS inhibitory moiety, facilitating the 
A
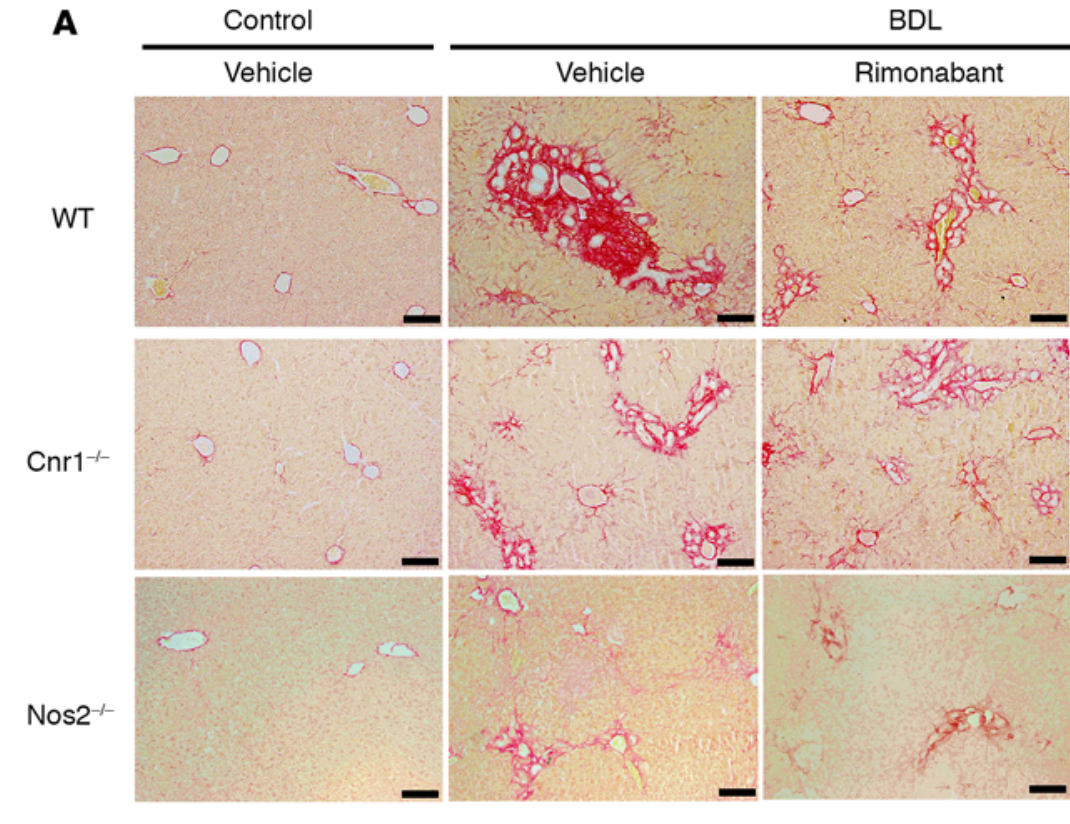

BDL

B
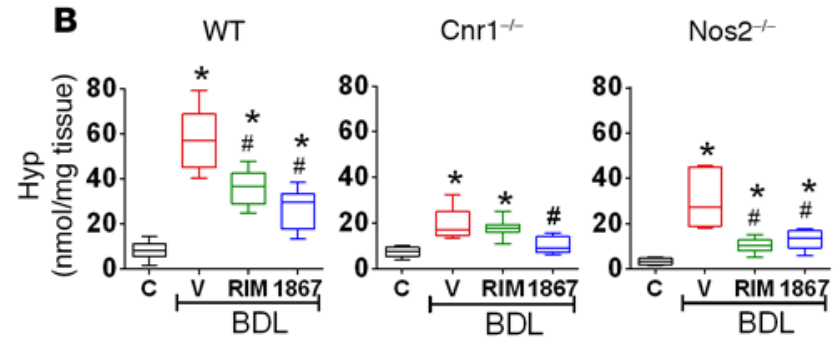

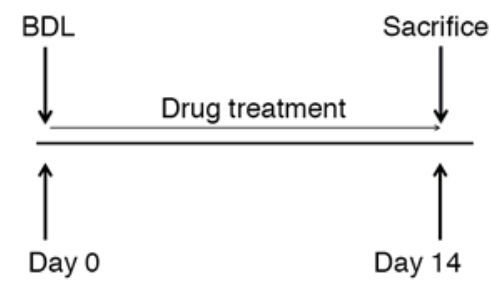

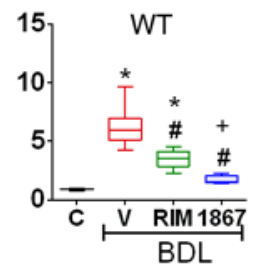
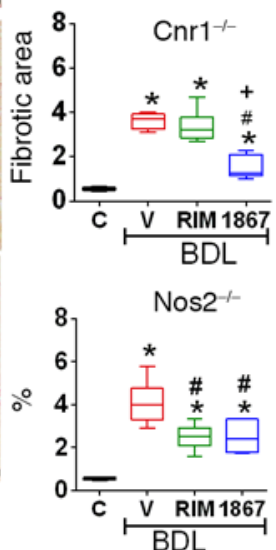

Figure 4. Effects of rimonabant or MRI-1867 on progression of biliary fibrosis. Wild-type, cnr1 $7^{-/-}$, and nos $2^{-/-}$mice received daily oral doses of 3 mg/kg of either compound for 2 weeks, starting on the day of bile duct ligation (BDL). (A) Liver fibrosis determined histologically by Sirius red staining; fibrosis area analyzed by computerized morphometry or (B) by hydroxyproline content. Scale bar: $100 \mu \mathrm{m}$. Data represent mean \pm SEM from 6 (nos $2^{-/-}$) or 9 mice/group (wt, $\left.\mathrm{cnr}^{-{ }^{--}}\right)$. Data in A and B were analyzed by 1-way ANOVA followed by Dunnett's multiple comparisons test. Significant difference from corresponding values in sham-operated controls ( $\left.{ }^{*} P<0.05\right)$, from values in vehicle-treated BDL group ( $\left.P<0.05\right)$, or between rimonabant and $\mathrm{MRI}-1867$-treated groups $\left({ }^{*} P<0.05\right)$.

delivery of the latter into hepatocytes and resulting in high target exposure. The chemical structure of the lead compound (-)-MRI-1867, from here on referred to as MRI-1867, and its physicochemical and pharmacological properties are illustrated in Figure 1. The absolute configuration of MRI-1867 was $4 S$, as indicated by the X-ray diffraction data (Supplemental Figure 3B). The low brain penetrance of MRI-1867 is reflected in its very low $(\sim 3 \%)$ brain/plasma $C_{\max }$ ratio after either acute or 28 -day chronic oral administration of the maximally efficacious dose of $3 \mathrm{mg} / \mathrm{kg}$, with no significant accumulation in the brain evident after chronic dosing (Figure 2A). Of note, the compound accumulated highly in the liver (Figure $2 \mathrm{~A}$ ), yet displayed no hepatotoxicity, as reflected by normal plasma levels of alanine aminotransferase (ALT) and aspartate aminotransferase (AST) following 28-day chronic administration of oral doses of 3 or $30 \mathrm{mg} / \mathrm{kg}$ (ALT: $28.5 \pm 1.3 \mathrm{U} / 1,31.8 \pm 4.8 \mathrm{U} / 1$, and $26.2 \pm 3.4 \mathrm{U} / 1$; AST: $39.7 \pm 5.4 \mathrm{U} / 1,44.0 \pm 6.1$ $\mathrm{U} / 1$, and $36.2 \pm 1.2 \mathrm{U} / 1$ in control, 3 , and $30 \mathrm{mg} / \mathrm{kg}$ drug groups, respectively). The low brain penetrance of MRI-1867 could be partly attributed to its increased polar surface area relative to rimonabant and ibipinabant (Table 1) but also to its being a substrate of p-glycoprotein-mediated reverse transport at the blood-brain barrier. This is suggested by an efflux ratio of 2.5 in a Caco-2 permeability assay (Supplemental Table 1) and further confirmed by the marked increase in its brain penetrance and brain $\mathrm{CB}_{1} \mathrm{R}$ occupancy, associated with a central $\mathrm{CB}_{1} \mathrm{R}$-mediated behavioral effect in $m d r 1 \alpha^{-/-}$mice (Supplemental Figure 4).

In the brain, $98.6 \%$ of MRI- 1867 is nonspecifically protein bound, as determined by equilibrium dialysis using brain membranes from $\mathrm{CBr}^{-/-}$mice. The brain concentration of unbound drug following acute or chronic oral dosing with $3 \mathrm{mg} / \mathrm{kg}$ was $0.2-0.3 \mathrm{nM}$, which is well below its $\mathrm{IC}_{50}$ of $40 \mathrm{nM}$ in a functional $(\mathrm{GTP} \gamma \mathrm{S})$ assay and its binding affinity for $\mathrm{CB}_{1} \mathrm{R}\left(\mathrm{K}_{\mathrm{i}}: 2.3 \mathrm{nM}\right.$, Figure $1 \mathrm{~B}$ and Table 1$)$. Even after treatment 
Table 1. Physicochemical and pharmacodynamic properties of MRI-1867

\begin{tabular}{|c|c|c|c|c|c|}
\hline & \multicolumn{3}{|c|}{ (-)-MRI-1867 } & Rimonabant & Ibipinabant \\
\hline cLogP & \multicolumn{3}{|c|}{6.1} & 6.01 & 6.16 \\
\hline tPSA & \multicolumn{3}{|c|}{100.5} & 50.16 & 74 \\
\hline $\mathrm{K}_{\mathrm{i}} \mathrm{CB}_{1} \mathrm{R}(\mathrm{nM})$ & $2.3 \pm 0.4$ & $8.0 \pm 2.0$ & $1.2 \pm 0.6$ & $4.5 \pm 1.0$ & $8.1 \pm 1.2$ \\
\hline $\mathrm{EC}_{50}, \mathrm{CB}_{1} \mathrm{R}$-induced $\left[{ }^{35} \mathrm{~S}\right] \mathrm{GTP} \gamma \mathrm{S}(\mathrm{nM})$ & $40 \pm 7$ & N.D. & N.D. & $25 \pm 5$ & $76 \pm 7$ \\
\hline Plasma protein binding (\%) & 99.6 & 99.88 & 99.86 & N.D. & N.D. \\
\hline
\end{tabular}

tPSA, total Polar Surface Area; N.D., not determined.

with a 10 times higher dose, unbound drug concentrations in the brain (0.9-1.2 nM) remained below the $\mathrm{K}_{1}$ for $\mathrm{CB}_{1} \mathrm{R}$ (Figure $2 \mathrm{~A}$ ). As a result, acute or chronic treatment of mice with 3-30 mg/kg MRI-1867 failed to cause significant displacement of a $\mathrm{CB}_{1} \mathrm{R}$ PET ligand (25) in in vivo PET imaging studies, whereas $3 \mathrm{mg} / \mathrm{kg}$ rimonabant caused significant, marked displacement (Figure 2B). Accordingly, MRI-1867 at doses up to 30 $\mathrm{mg} / \mathrm{kg}$ did not induce anxiety-like behavior in the elevated plus maze, an effect triggered by $\mathrm{CB}_{1} \mathrm{R}$ blockade in the CNS, whereas rimonabant caused pronounced anxiety at $3 \mathrm{mg} / \mathrm{kg}$ (Figure 2C).

The inverse agonist properties of MRI-1867 were documented both in vitro using the GTP $\gamma \mathrm{S}$ binding assay and in vivo using a functional assay to quantify $\mathrm{CB}_{1} \mathrm{R}$-mediated changes in upper gastrointestinal motility (26). In the absence of an agonist, MRI-1867 caused concentration-dependent decreases in GTP $\gamma \mathrm{S}$ binding, and at oral doses of

Col1a
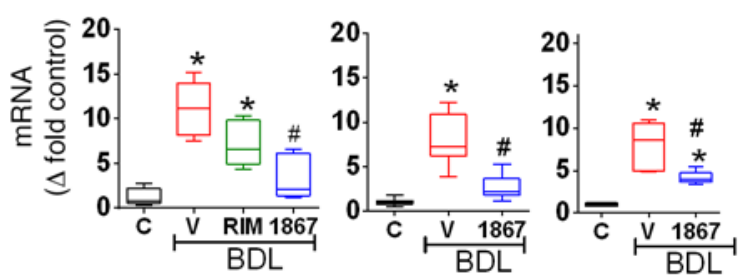

$\operatorname{Tgf\beta } 1$
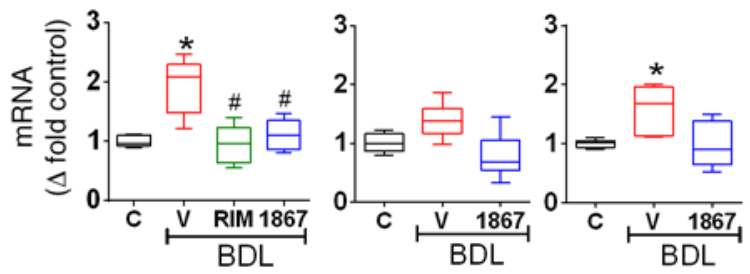

Timp1
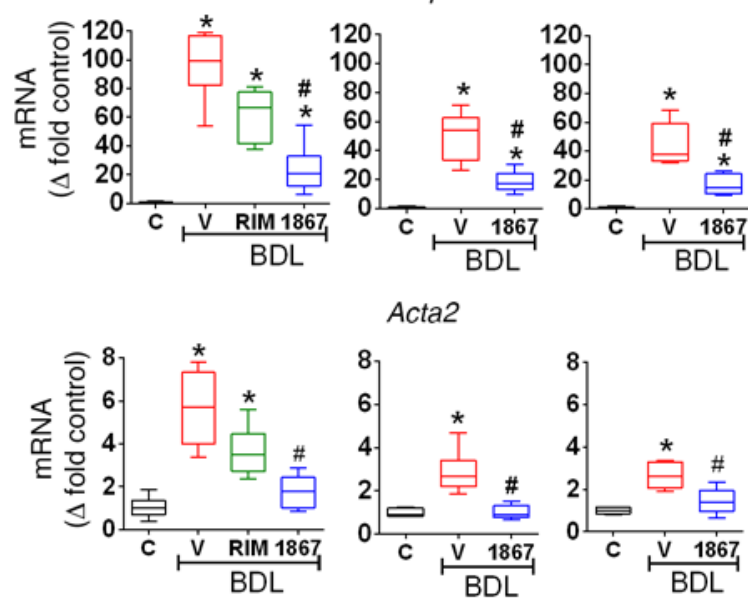

Acta2

WT
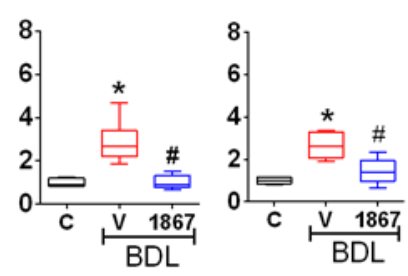

$\mathrm{Cnr}^{+-}$

Nos2-$3-10 \mathrm{mg} / \mathrm{kg}$, it significantly increased upper GI motility in control but not in $\mathrm{CBr}^{-/-}$mice, both effects indicating inverse agonism at $\mathrm{CB}_{1} \mathrm{R}$ (Supplemental Figure 5, A and C). The same assays were used to assess competitive antagonism of $\mathrm{CB}_{1} \mathrm{R}$ by MRI-1867, which concentration-dependently inhibited GTP $\gamma \mathrm{S}$ binding stimulated by $300 \mathrm{nM}$ of the $\mathrm{CB}_{1} \mathrm{R}$ agonist, $\mathrm{CP}-55,940$, and also dose-dependently reversed the inhibition of upper GI motility caused by a $10 \mathrm{mg} / \mathrm{kg}$ dose of the $\mathrm{CB}_{1} \mathrm{R}$ agonist, arachidonoyl 2-chloroethylamide, with rimonabant causing similar inhibition in the same dose or concentration range (Supplemental Figure 5, B and D). So, in subsequent experiments, a daily oral dose of $3 \mathrm{mg} / \mathrm{kg}$ was used for both compounds.

The acetamidine metabolite and the cleaved chemical scaffold were both detectable by LC-MS/MS in the supernatant of mouse liver microsomes incubated with $3 \mu \mathrm{M}$ MRI-1867, indicating that acetamidine is generated by hepatic metabolism of MRI-1867 (Figure 3A). These two metabolites could also be detected in peripheral blood plasma 1 hour after oral administration of MRI-1867 (data not shown). Both MRI-1867 and its leaving group acetamidine caused concentration-dependent inhibition of iNOS activity in the $1-10 \mu \mathrm{M}$ range when tested in vitro in cell-free extracts of RAW 264.7 mouse macrophages treated with LPS $+\gamma$-interferon to induce iNOS expression

Figure 5. Effects of rimonabant and MRI-1867 on gene expression of fibrosis markers. Wild-type, $\mathrm{Cnr}^{-1 /}$, and nos2 $2^{-/-}$mice received daily oral doses of $3 \mathrm{mg} / \mathrm{kg} / \mathrm{d}$ of either compound for 2 weeks, starting on the day of bile duct ligation (BDL). Gene expression of collagen 1a (col1a), transforming growth factor- $\beta 1$ (tgf $\beta 1$ ), $\alpha$-smooth muscle actin (acta2), and tissue inhibitor of metalloproteinase-1 (timp1) was assayed by real-time PCR. Data repre-

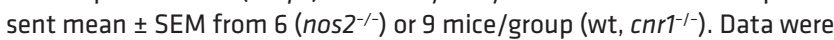
analyzed by 1-way ANOVA followed by Dunnett's multiple comparisons test. Significant difference from corresponding values in sham-operated controls $\left({ }^{*} P<0.05\right)$ or from values in vehicle-treated BDL group $\left({ }^{*} P<0.05\right)$. 
A
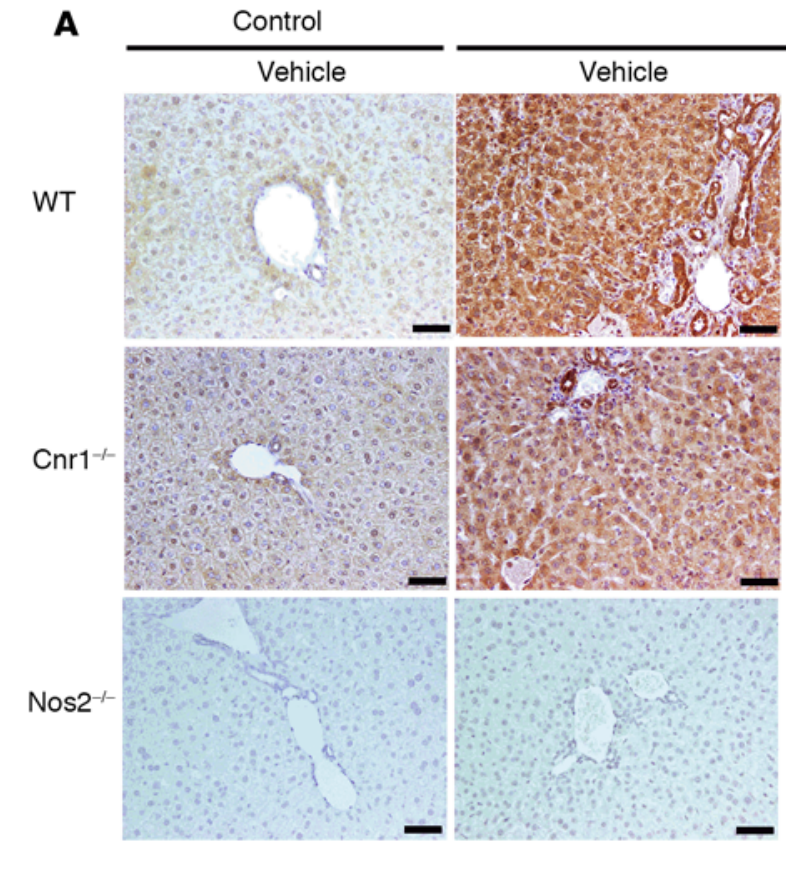

B

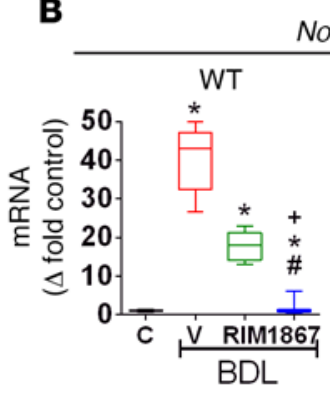

Nos2
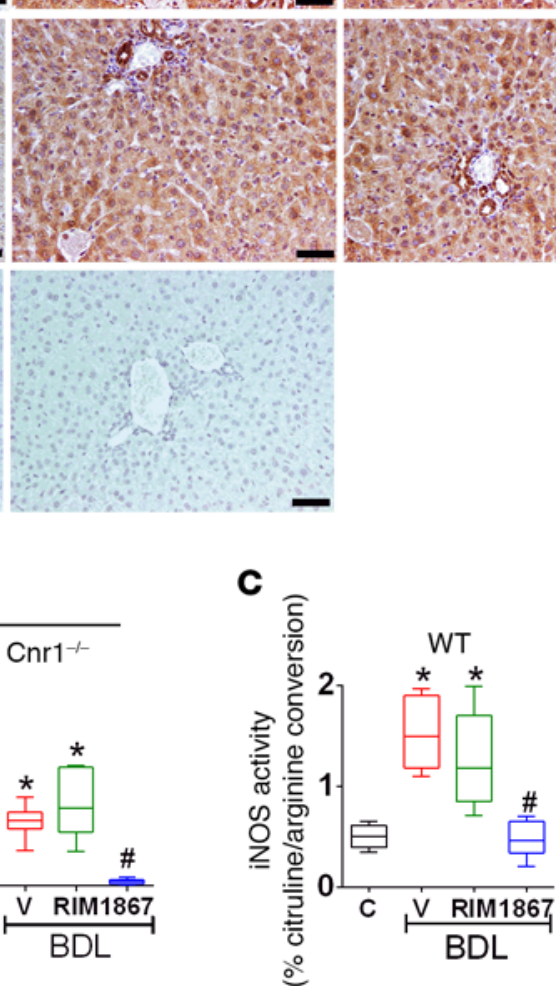

BDL
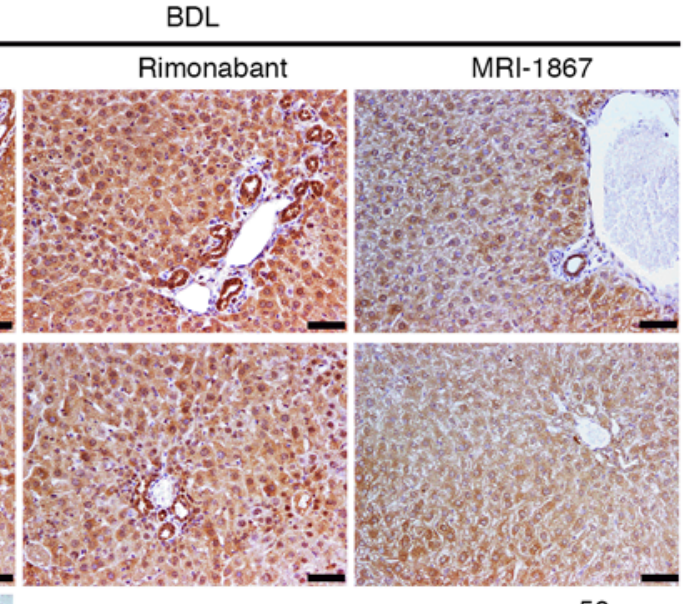

50 um
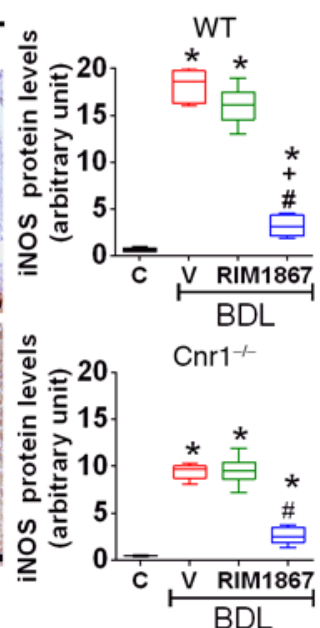

D

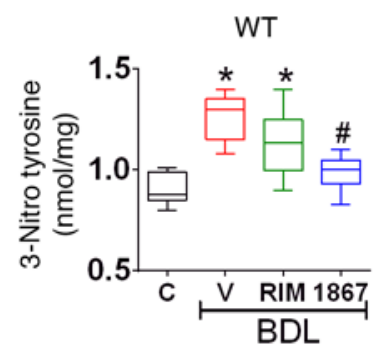

$\mathbf{F}$
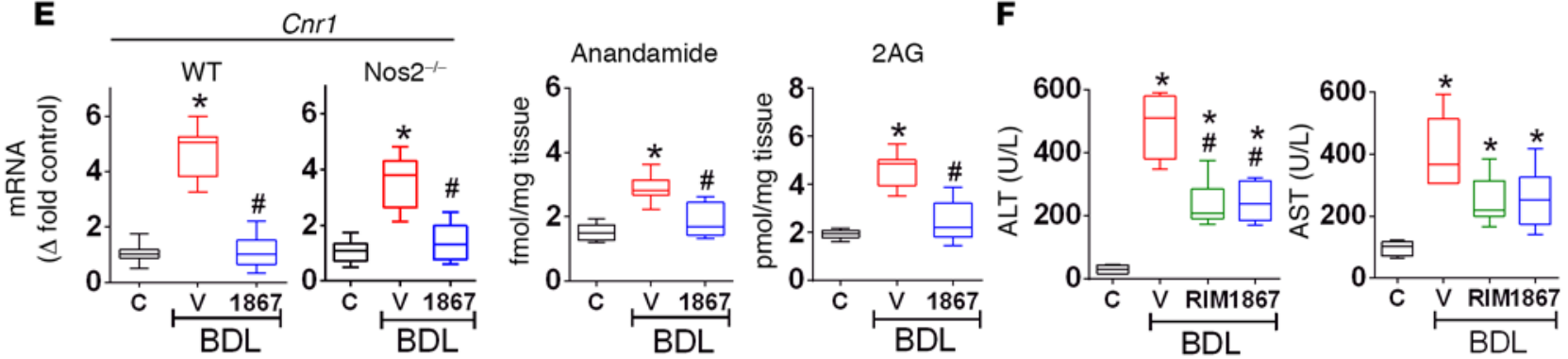

Figure 6. Attenuation of hepatic iNOS activity and protein levels in biliary fibrosis by MRI-1867 but not rimonabant. (A) Immunostaining for iNOS protein in wild-type, $\mathrm{Cnr1}^{-1-}$, or nos $2^{-1-}$ mice. Scale bar: $50 \mu \mathrm{m}$. (B) nos2 mRNA in wild-type or $\mathrm{Cnr1}^{-1-}$ mice. (C) Hepatic iNOS enzyme activity, as measured by the conversion of arginine to citrulline (see Methods). (D) Hepatic 3-nitrotyrosine levels. (E) Effects of MRI-1867 on hepatic CB, R mRNA and endocannabinoid levels in bile duct ligation (BDL) mice. (F) Effect of treatments on serum ALT and AST in wild-type mice with BDL. Mean \pm SEM from 9 (wt), 9 ( $\left(\mathrm{cnr} 7^{-/-}\right.$), or 6 mice $\left(n o s 2^{-1-}\right)$ are shown. Data were analyzed by 1-way ANOVA followed by Dunnett's multiple comparisons test. Significant difference from corresponding values in sham-operated controls ( $\left.{ }^{*} P<0.05\right)$, from values in vehicle-treated BDL group $\left({ }^{*} P<0.05\right)$, or between rimonabant and MRI-1867-treated groups $\left({ }^{+} P<0.05\right)$.

(Figure 3B). Note that the inhibitory concentrations are below the peak hepatic concentration of unmetabolized MRI-1867 following its acute or chronic administration at a therapeutically efficacious dose (Figure 2A). In contrast, rimonabant at up to $100 \mu \mathrm{M}$ did not inhibit iNOS. Finally, the inhibitory effects were selective for iNOS, as endothelial NOS (eNOS) activity was unaffected by MRI-1867 or acetamidine (Figure 3C).

Druggable properties of MRI-1867. The oral bioavailability of MRI-1867 was $81 \%$, defined as the ratio of AUC following oral gavage versus intravenous administration of a $3 \mathrm{mg} / \mathrm{kg}$ dose in Sprague-Dawley 
A

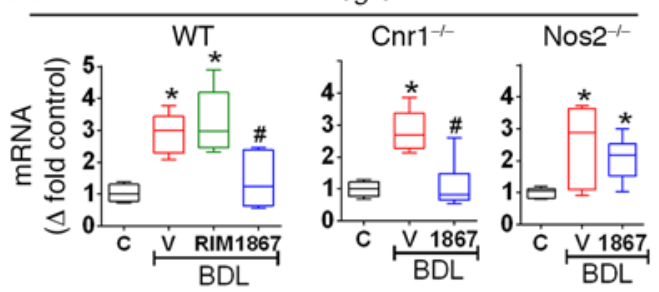

Pdgfrb

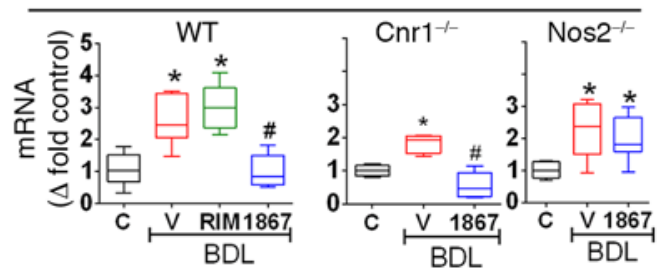

\section{CD248/endosialin}
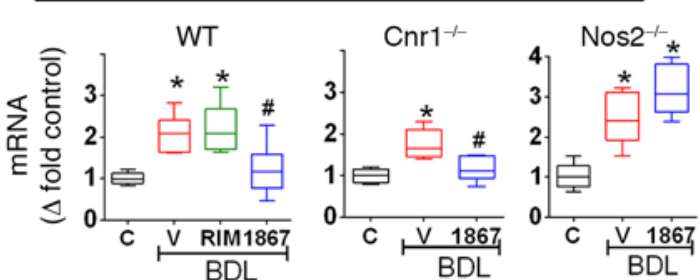

B

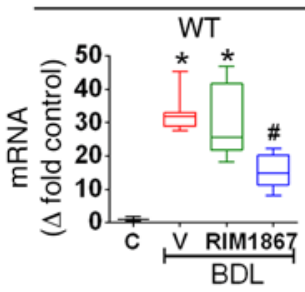

$\alpha V \beta 6$

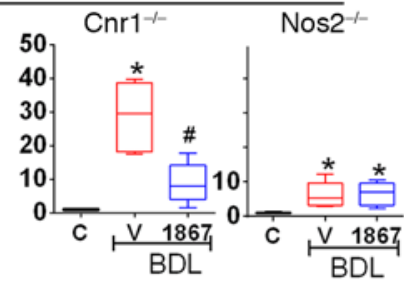

C

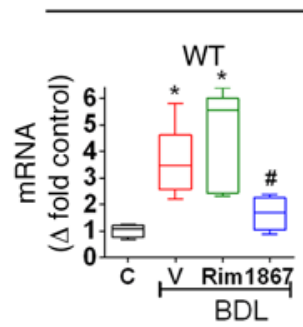

Nirp3
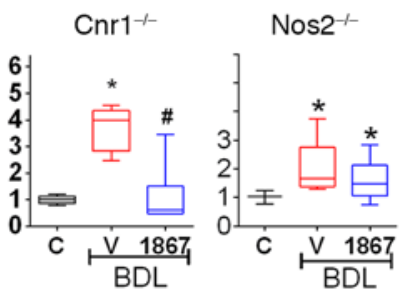

Control

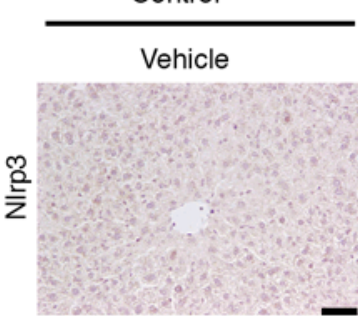

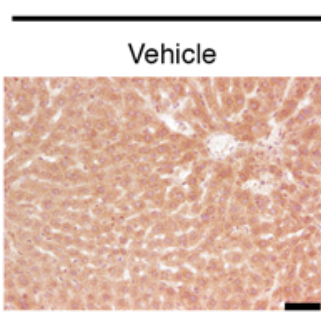

$\mathrm{BDL}$

Rimonabant

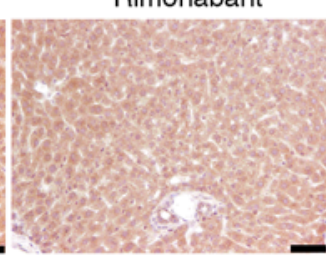

Figure 7. CB, $R$-independent profibrotic pathways targeted by MRI-1867. Effects of MRI-1867 and rimonabant on (A) pdgfb/pdgfbr/cd248, (B) $\alpha \vee \beta 6$, and (C) asc3/nlrp3 pathways in wild-type, $\mathrm{Cnr}^{-/}$, and nos2 $2^{-/}$mice with bile duct ligation (BDL). Note that MRI1867 but not rimonabant reverses $\mathrm{BDL}$-induced increases in gene expression and (D) NIrp3 protein levels, and its inhibitory effect is retained in $\mathrm{Cnr1}^{-/-}$but lost in nos2 $2^{-/-}$mice. Scale bar: $100 \mu \mathrm{m}$. Mean \pm SEM from 6 mice/group. Data were analyzed by 1-way ANOVA followed by Dunnett's multiple comparisons test. Significant difference from corresponding values in sham-operated controls $\left({ }^{*} P<0.05\right)$, from values in vehicle-treated BDL group $\left({ }^{\#} P<0.05\right)$, or between rimonabant and MRI-1867-treated groups $\left({ }^{+} P<0.05\right)$.

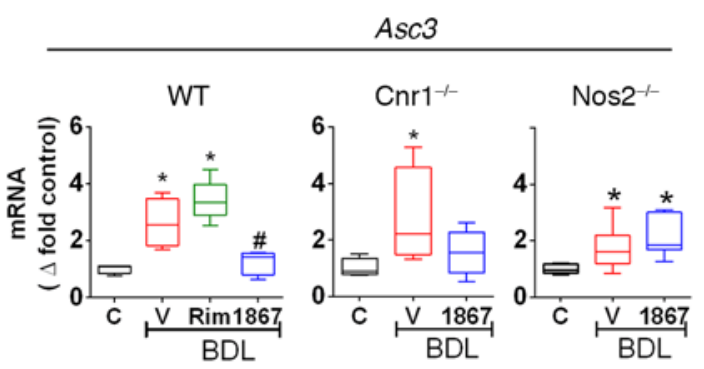


A
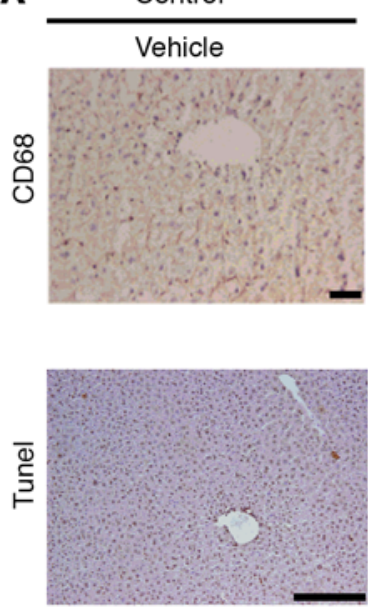

B

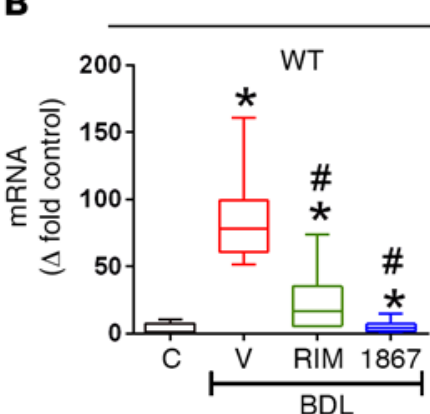

BDL
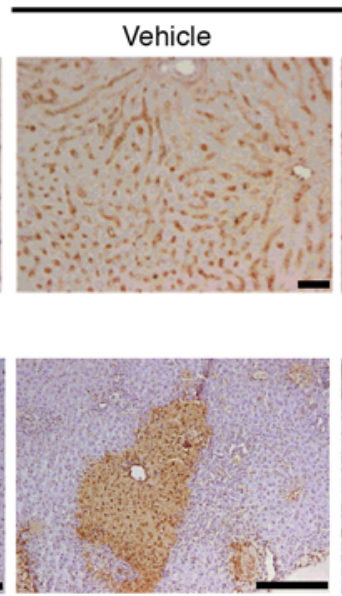

Ccl2

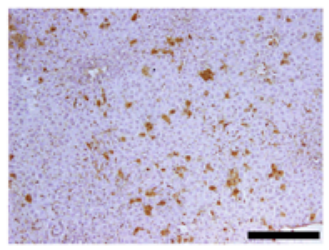

Rimonabant

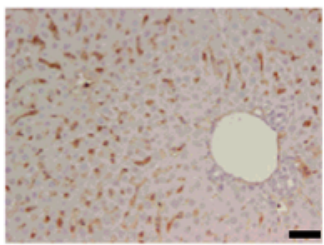

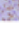

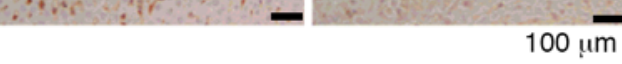

$100 \mu \mathrm{m}$

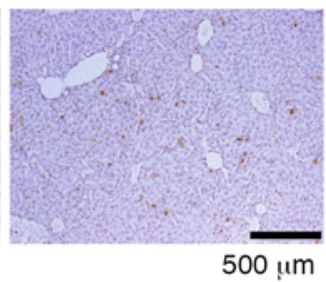

$500 \mu \mathrm{m}$
MRI-1867
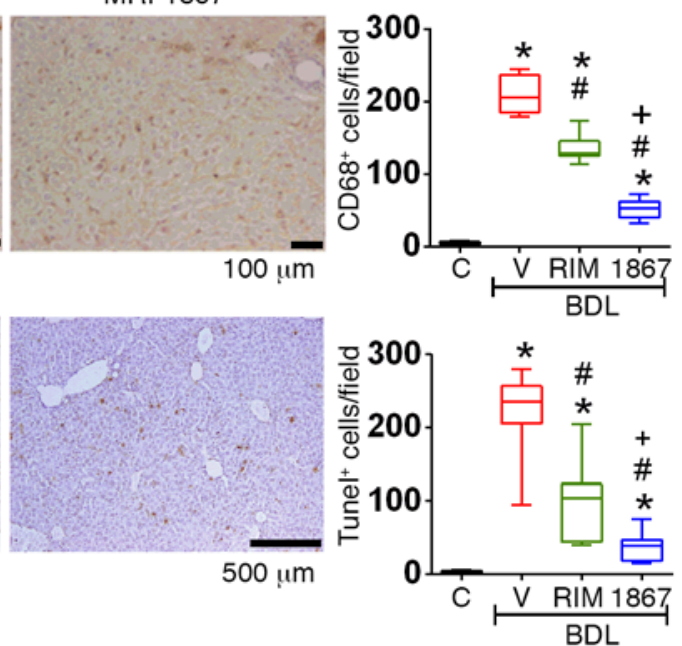

Figure 8. Differential effects of rimonabant and MRI-1867 on macrophage infiltration in the fibrotic liver. (A) CD68 ${ }^{+}$macrophages (scale bar: $100 \mu \mathrm{m}$ ) and tunel-positive apoptotic cells (scale bar: $50 \mu \mathrm{m}$ ) in the liver; effects of bile duct ligation (BDL) and chronic treatment of BDL mice with rimonabant or MRI-1867. (B) Ccl2 gene expression in the livers of the same animals. Mean \pm SEM from $n=8(w t), n=8(B D L+V), n=7(B D L+$ rimo), and $n=7(B D L+M R I)$ Data were analyzed by 1-way ANOVA followed by Dunnett's multiple comparisons test. Significant difference from corresponding values in sham-operated controls ( $\left.{ }^{*} P<0.05\right)$, from values in vehicle-treated BDL group $\left({ }^{*} P<0.05\right)$, or between rimonabant and MRI-1867-treated groups $\left({ }^{+} P<0.05\right)$.

rats. Plasma $t_{1 / 2}$ was $\sim 4$ hours for orally administered MRI-1867 in both mice and rats. Microsomal stability assays, using mouse, rat, or human liver microsomal preparations indicated that $46 \%-62 \%$ of the compound remained unmetabolized following 1 hour of incubation at $37^{\circ} \mathrm{C}$ (Supplemental Table 2). A 2 -strain Ames test for in vitro genotoxicity was negative at a dose of up to $125 \mu \mathrm{g} / \mathrm{ml} \mathrm{MRI-1867}$ (Supplemental Table 3). In an in vitro assay, the $\mathrm{IC}_{50}$ of MRI-1867 for inhibition of the $\mathrm{K}^{+}$current mediated by hERG (human ether-à-go-go-related gene) was $5.1 \mu \mathrm{M}$ (Supplemental Table 4). One $\mu \mathrm{M}$ MRI-1867 was also tested in a safety screen, including selected receptors, ion channels, and enzymes (Cerep), and the only positive hit other than $\mathrm{CB}_{1} \mathrm{R}(93 \%$ displacement) was for the $\kappa$ opioid receptor $(61 \%$ displacement, Supplemental Table 5). However, in a functional screen testing for agonist as well as antagonist activity, the same concentration of MRI-1867 did not interact with the $\kappa$ opioid receptor or with any of a series of 192 GPCRs other than CB $_{1}$ R (Supplemental Table 6). Finally, MRI-1867 has $>500$-fold selectivity for $\mathrm{CB}_{1} \mathrm{R}$ over $\mathrm{CB}_{2} \mathrm{R}$ (Figure $1 \mathrm{~B}$ ).

Antifibrotic activity of MRI-1867 in bile duct ligation-induced liver fibrosis. We compared the antifibrotic effects of rimonabant and MRI-1867 in two murine models of liver fibrosis with different etiologies, induced either by bile duct ligation (BDL) or carbon tetrachloride $\left(\mathrm{CCl}_{4}\right)$ treatment.

$\mathrm{BDL}$ is an experimental model featuring biliary fibrosis and cirrhosis with periportal hepatocyte death (27). The BDL model is relevant to clinical entities such as extrahepatic biliary atresia and primary sclerosing cholangitis, in which the liver injury is associated with interruption of bile flow to the gut. In this model, the irreversible nature of liver injury enables one to determine its drug-induced regression. Therefore, we have used two different treatment paradigms. To assess the prevention of fibrosis, treatments 


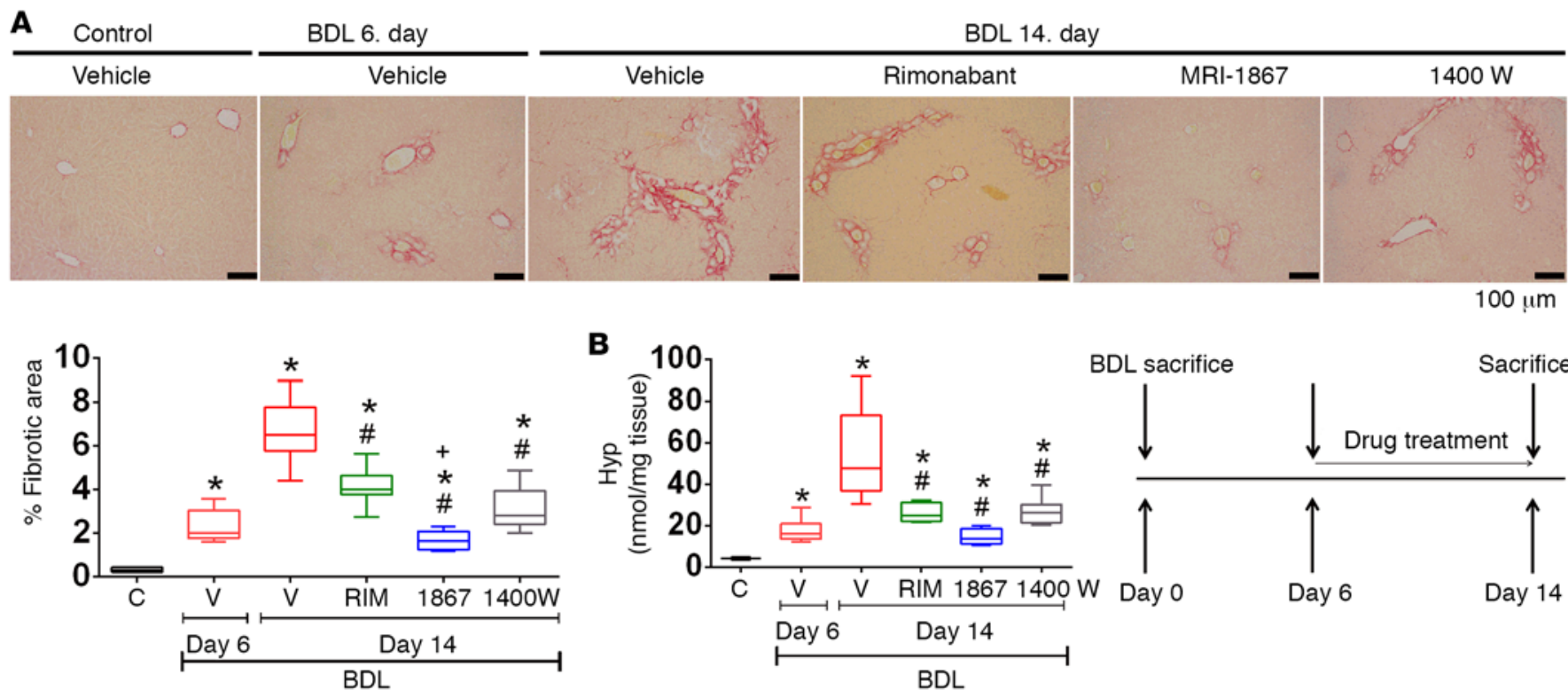

Figure 9. Effect of rimonabant, MRI-1867, and iNOS inhibitor 1400W on regression of biliary fibrosis. Wild-type mice with bile duct ligation (BDL) were sacrificed at day 6 after BDL or treated with daily oral doses of vehicle, $3 \mathrm{mg} / \mathrm{kg} / \mathrm{d}$ of rimonabant or MRI-1867, or $10 \mathrm{mg} / \mathrm{kg} / \mathrm{d}$ of $1400 \mathrm{~W}$ starting on day 6 after BDL to assess fibrosis regression. (A) Liver fibrosis was analyzed by Sirius red staining and quantified by morphometry and by (B) hydroxyproline content. Scale bar: $100 \mu \mathrm{m}$. Data represent mean \pm SEM, $n=5$ (control), $n=5$ (BDL + V), 8 (BDL + rimo), $n=8$ (BDL + 1867), and $n=8$ (BDL + 1400W) mice/group. Data were analyzed by 1-way ANOVA followed by Dunnett's multiple comparisons test. Significant difference from corresponding values in sham-operated controls ( $\left.{ }^{*} P<0.05\right)$, from values in vehicle-treated BDL group $\left({ }^{\#} P<0.05\right)$, or between rimonabant and MRI-1867-treated groups $\left({ }^{+} P<0.05\right)$.

started immediately after fibrogenesis initiation by BDL surgery. As for mitigating established fibrosis, in preliminary studies we determined that marked fibrosis was evident within 6 days of the ligation of the common bile duct, and it showed very low intersubject variability, so attenuation of fibrosis was tested by starting drug treatments on day 6 after BDL. The potential role of the secondary target iNOS in the antifibrotic activity of MRI-1867 was assessed in two ways: first, by comparing its antifibrotic efficacy with that of an equipotent $\mathrm{CB}_{1} \mathrm{R}$ inhibitory dose of rimonabant, and second, by testing its effects in $\mathrm{CB}_{1} \mathrm{R}$ knockout $\left(\mathrm{cnr}^{-/-}\right)$as well as iNOS knockout (nos2 $\left.2^{--}\right)$mice with BDL-induced fibrosis.

MRI-1867 was significantly more efficacious than rimonabant, both dosed at $3 \mathrm{mg} / \mathrm{kg} / \mathrm{d}$, in preventing the progression of BDL-induced collagen deposition in the liver, as quantified histologically by Sirius red staining (Figure 4A) and biochemically by measuring hydroxyproline (Hyp) content (Figure 4B). BDL also induced marked ductular proliferation, which was again attenuated significantly more effectively by MRI1867 than by rimonabant (Supplemental Figure 6). Compared with wild-type mice, BDL-induced fibrosis

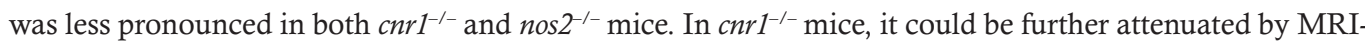
1867 but not by rimonabant, whereas in nos $2^{-/-}$mice, the 2 compounds had similar antifibrotic efficacy (Figure 4A). In wild-type mice with BDL, both compounds significantly reduced the gene expression of the fibrosis markers collagen-1, Tgf $\beta 1, \alpha$-smooth muscle actin ( $\alpha \mathrm{Sma}$ ), and tissue inhibitor of metalloprotease- 1 (Timp1), with MRI-1867 being significantly more effective than rimonabant. Its effects were retained in $\mathrm{cnrl}^{-1-}$ mice (Figure 5).

BDL induced a robust increase in iNOS expression in the liver. This was documented by iNOS immunostaining evident in hepatocytes (Figure 6A) as well as iNOS gene expression (Figure 6B); both were completely prevented by MRI-1867 in both wild-type and $\mathrm{cnr}^{-/-}$mice, whereas rimonabant did not affect iNOS protein levels and only partially reduced iNOS gene expression. These findings were in accordance with the similar increase in BDL-induced iNOS expression in the wild-type and $\mathrm{Cnr}^{1^{-1}-}$ liver (Figure 6, A and B). The specificity of iNOS immunostaining was indicated by its absence in nos $2^{-/-}$mice (Figure 6A). MRI-1867 also completely prevented the BDL-induced increase in iNOS function, as quantified by hepatic iNOS enzyme activity (Figure 6C) or hepatic protein nitrosylation (Figure 6D), with rimonabant having no significant effect in either assay. BDL also increased $c n r 1$ expression and hepatic endocannabinoid levels, and these changes were reversed by MRI-1867 treatment (Figure 6E). These effects are likely due to $\mathrm{CB}_{1} \mathrm{R}$ 

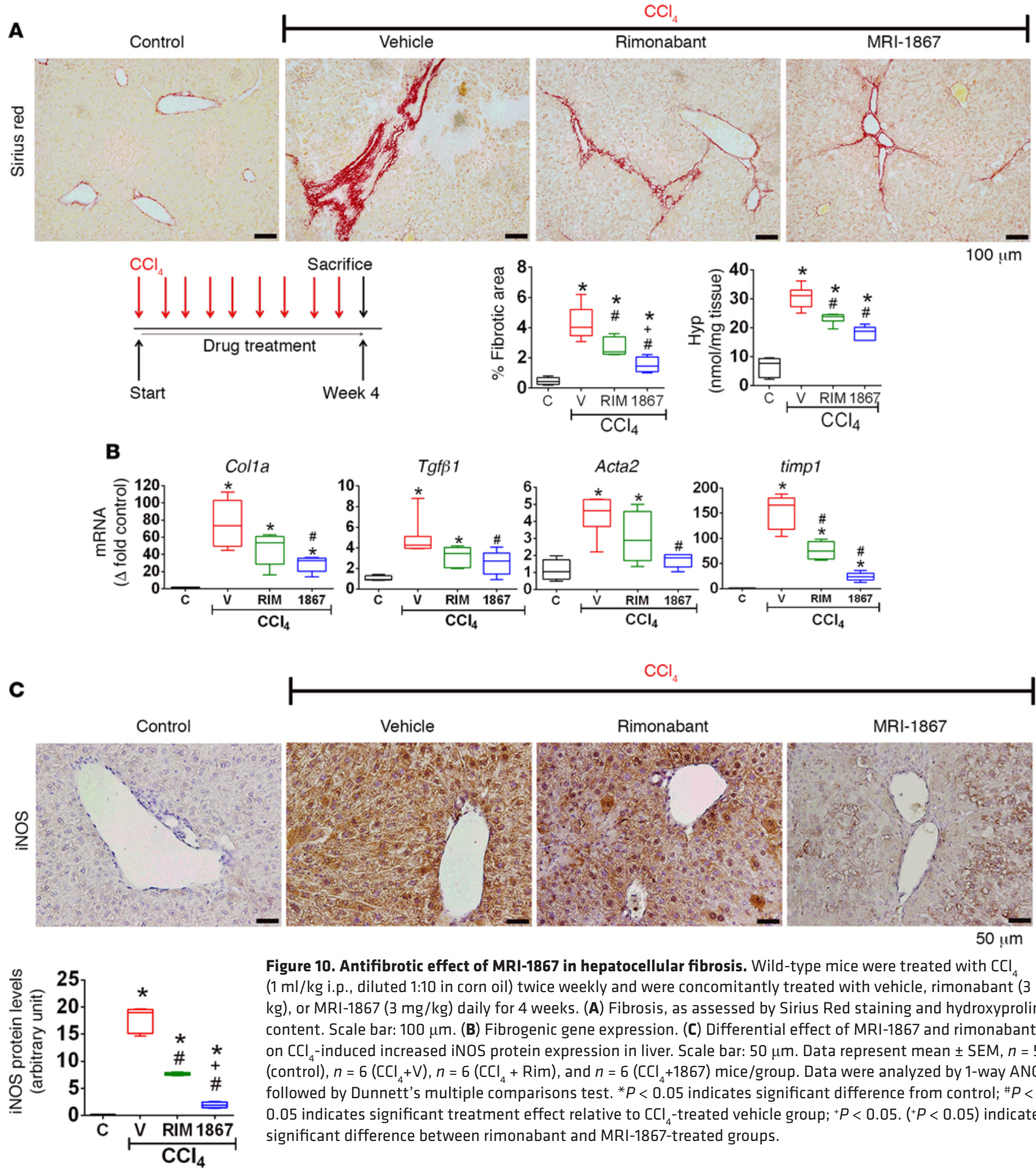

Figure 10. Antifibrotic effect of MRI-1867 in hepatocellular fibrosis. Wild-type mice were treated with $\mathrm{CCl}_{4}$ $(1 \mathrm{ml} / \mathrm{kg}$ i.p., diluted 1:10 in corn oil) twice weekly and were concomitantly treated with vehicle, rimonabant ( $3 \mathrm{mg} /$ $\mathrm{kg}$ ), or MRI-1867 (3 mg/kg) daily for 4 weeks. (A) Fibrosis, as assessed by Sirius Red staining and hydroxyproline content. Scale bar: $100 \mu \mathrm{m}$. (B) Fibrogenic gene expression. (C) Differential effect of MRI-1867 and rimonabant on $\mathrm{CCl}_{4}$-induced increased iNOS protein expression in liver. Scale bar: $50 \mu \mathrm{m}$. Data represent mean $\pm \mathrm{SEM}, n=5$ (control), $n=6\left(\mathrm{CCl}_{4}+\mathrm{V}\right), n=6\left(\mathrm{CCl}_{4}+\mathrm{Rim}\right)$, and $n=6\left(\mathrm{CCl}_{4}+1867\right)$ mice/group. Data were analyzed by 1-way ANOVA followed by Dunnett's multiple comparisons test. ${ }^{*} P<0.05$ indicates significant difference from control; ${ }^{\#}<$ 0.05 indicates significant treatment effect relative to $\mathrm{CCl}_{4}$-treated vehicle group; ${ }^{+} P<0.05$. $\left({ }^{+} P<0.05\right)$ indicates significant difference between rimonabant and MRI-1867-treated groups.

blockade, as judged by similar effects reported with rimonabant (28). CB1R blockade also appears to be responsible for the attenuation of the elevated plasma AST and AST levels by both antagonists (Figure 6F).

The antifibrotic activity of MRI-1867 in $\mathrm{CB}_{1} \mathrm{R}^{-/}$mice suggests that in addition to sharing some targets with $\mathrm{CB}_{1} \mathrm{R}$, iNOS can also uniquely target fibrotic processes not affected by $\mathrm{CB}_{1} \mathrm{R}$. The criteria used to identify such targets in mice with BDL-induced fibrosis included the inhibition of their increased gene expression in wild-type mice by MRI-1867 but not by rimonabant and the inhibitory effect of MRI-1867 remaining unchanged in $\mathrm{cnrl}^{-1-}$ mice but being absent in nos $2^{-1-}$ mice. As illustrated in Figure 7, we have identified multiple fibrogenic targets that meet these criteria: the PDGF/PDGFR $\beta$ system (29) and its 
downstream mediator CD248 (endosialin) (30), which promote the differentiation of quiescent stellate cells into profibrotic myofibroblasts (Figure 7A); $\alpha \mathrm{v} \beta 6$ integrin, which is expressed in activated epithelial cells and is a marker of the progression of biliary and portal fibrosis as well as an activator of latent TGF- $\beta$ (31) (Figure 7B); and the Nlrp3 inflammasome and its associate protein Asc3, which play a prominent role in liver inflammation associated with drug- or obesity-related liver fibrosis (32) (Figure 7C). Unique activation of these pathways by iNOS but not by $\mathrm{CB}_{1} \mathrm{R}$ may contribute to the differential antifibrotic efficacy of MRI-1867 and rimonabant.

$\mathrm{BDL}$ was associated with marked infiltration of the liver by $\mathrm{CD} 68^{+}$macrophages (Figure $8 \mathrm{~A}$ ), probably driven by the elevated levels of the chemokine $\mathrm{Ccl} 2$ (Figure $8 \mathrm{~B}$ ) and causing hepatocellular damage, as indicated by the parallel increase in apoptotic cells (Figure 8A). Macrophage infiltration and hepatocyte apoptosis as well as the elevated levels of Ccl2 were more effectively suppressed by MRI-1867 than by rimonabant, and MRI-1867 remained effective in $\mathrm{cnrl}^{-1-}$ but not in nos $2^{-/-}$mice (Figure 8B). Furthermore, MRI-1867 but not rimonabant was able to completely arrest the progression, with a tendency to reverse BDL-induced liver fibrosis when treatment was started on day 6 after BDL (Figure 9). Daily treatment with a near-maximal inhibitory dose of $10 \mathrm{mg} / \mathrm{kg}$ of the iNOS inhibitor $1400 \mathrm{~W}$ attenuated fibrosis to the same extent as rimonabant but was less effective than MRI-1867. BDL-induced fibrosis involved marked bridging, which remained evident in rimonabant- or $1400 \mathrm{~W}$-treated treated mice but was practically abolished/ prevented by MRI-1867 in both treatment paradigms (Figure 4A and Figure 9).

Antifibrotic activity of MRI-1867 in $\mathrm{CCl}_{4}$-induced liver fibrosis. $\mathrm{CCl}_{4}$-induced fibrosis is widely used as a chemically induced liver fibrosis model, which features centrilobular hepatocyte death (27). As fibrosis induced by short-term ( $<8$ weeks) $\mathrm{CCl}_{4}$ remains reversible, this model is suitable to determine drug-induced prevention but not reversal of fibrosis. Mice were treated twice weekly for 4 weeks with $1 \mathrm{ml} / \mathrm{kg} \mathrm{CCl}_{4}$ to induce liver fibrosis (27) and simultaneously treated with vehicle, MRI-1867 (3 mg/kg/d), or rimonabant ( $3 \mathrm{mg} / \mathrm{kg} / \mathrm{d}$ ). Fibrosis was attenuated significantly more by MRI-1867 than by rimonabant, as documented histologically by Sirius red staining (Figure 10A), by the reduced hepatic Hyp content, fibrogenic gene expression (Figure 10B), and iNOS protein expression (Figure 10C).

Finally, we tested MRI-1867 for attenuating obesity and its metabolic consequences, known predisposing factors for liver fibrosis, based on the documented effectiveness of other peripherally restricted $C_{1} R$ antagonists in mouse models of obesity $(12,33)$. In C57BL6/J mice with high-fat diet-induced obesity, chronic treatment with MRI-1867 caused dose-dependent reductions in body weight, hepatic steatosis, and improved glucose tolerance (Supplemental Figure 7).

\section{Discussion}

We have introduced a type of peripherally restricted hybrid compound that simultaneously acts on two targets previously associated with the development and progression of liver fibrosis of different etiologies, $\mathrm{CB}_{1} \mathrm{R}$ and iNOS. Using MRI-1867, a potent, orally bioavailable, non-brain-penetrant $\mathrm{CB}_{1} \mathrm{R}$ inverse agonist with additional activity as a direct inhibitor of iNOS, we demonstrate that the engagement of the secondary target results in a $\mathrm{CB}_{1} \mathrm{R}$-independent increase in antifibrotic efficacy relative to the efficacy of the single-target $\mathrm{CB}_{1} \mathrm{R}$ antagonist rimonabant in mouse models of both hepatocellular and biliary fibrosis.

The hybrid compound has unique pharmacokinetic as well as pharmacodynamic features. As for pharmacokinetics, its limited access to $\mathrm{CB}_{1} \mathrm{R}$ in the brain minimizes its ability to elicit behavioral effects predictive of neuropsychiatric side effects in humans, thus avoiding the pitfall that plagued first-generation, brain-penetrant $\mathrm{CB}_{1} \mathrm{R}$ antagonists. The lack of detectable occupancy of $\mathrm{CB}_{1} \mathrm{R}$ in the brain at doses up to 10 times the efficacy dose was demonstrated in real time by $\mathrm{CB}_{1} \mathrm{R}$ PET, which indicates a favorable therapeutic index regarding centrally mediated adverse effects. Features that limit the brain penetrance of the hybrid compound include an increase in its polar surface area as well as its being a substrate of the P-glycoprotein-mediated reverse transport through the blood-brain barrier, the latter indicated by its increased brain penetrance in $m d r 1 \alpha$-deficient mice.

Furthermore, by incorporating the iNOS inhibitory polar acetamidine moiety into the apolar core chemical scaffold, one could overcome the lack of oral bioavailability of acetamidine, yielding very high target organ exposure through the hepatic uptake and accumulation of the parent compound or "pro-drug," from which the acetamidine moiety is released through metabolic cleavage. Of note, the very high hepatic concentration of the hybrid inhibitor is not associated with hepatotoxicity, as reflected by unchanged plasma ALT and AST levels in mice chronically treated with MRI-1867. 
Regarding the pharmacodynamics of the hybrid $\mathrm{CB}_{1} \mathrm{R} / \mathrm{iNOS}$ inhibitor, two important principles have emerged from efforts to develop effective antifibrotic therapies. First, antifibrotic treatment strategies could aim to control the primary disease, to inhibit fibrogenic gene expression and signaling, to promote molecular mechanisms involved in fibrosis regression, or a combination of these (1). Second, with multiple molecular mechanisms and signaling pathways involved in fibrosis, targeting more than one could increase antifibrotic efficacy (34), and the hybrid $\mathrm{CB}_{1} \mathrm{R} / \mathrm{iNOS}$ inhibitor embodies optimal characteristics on both accounts.

As to the first principle, both the endocannabinoid $/ \mathrm{CB}_{1} \mathrm{R}$ system and iNOS are ideal targets, as they are known to be involved directly in the fibrotic process and also in the conditions predisposing to liver fibrosis, as detailed in the Introduction. An emerging major predisposing factor to liver fibrosis is nonalcoholic fatty liver disease (35), and $\mathrm{CB}_{1} \mathrm{R}$ blockade has proven effective in mitigating obesity-related hepatic steatosis in both rodent models (36) and humans (37). The other two major predisposing factors, alcoholic fatty liver disease and viral hepatitis, also involve increased $\mathrm{CB}_{1} \mathrm{R}$ activity. Hepatic $\mathrm{CB}_{1} \mathrm{R}$ expression is induced either by chronic ethanol intake (7) or the hepatitis $\mathrm{C}$ virus (38), and $\mathrm{CB}_{1} \mathrm{R}$ blockade mitigates alcohol-induced steatosis (7) and inhibits hepatitis $C$ virus production (39). The demonstrated ability of MRI-1867 to attenuate diet-induced obesity and its metabolic consequences may also contribute to its efficacy in mitigating liver fibrosis when obesity is a contributing factor. Furthermore, $\mathrm{CB}_{1} \mathrm{R}$ blockade has therapeutic potential not only in conditions that predispose to fibrosis, but also in hepatocellular carcinoma (40), which has been epidemiologically linked to progressive liver fibrosis $(41,42)$.

In addition to mitigating predisposing factors, $\mathrm{CB}_{1} \mathrm{R}$ blockade can also directly engage profibrotic gene expression and signaling in the liver, inhibition of which has been shown to contribute to the therapeutic efficacy of $\mathrm{CB}_{1} \mathrm{R}$ blockade $(11,43-46)$, cnrl gene deletion (47), or RNAi-mediated cnr1 knockdown (48) in models of liver fibrosis without underlying obesity. Furthermore, $\mathrm{CB}_{1} \mathrm{R}$ antagonism increases the expression of matrix metalloprotease-1 (49) involved in extracellular matrix degradation and decreases the expression of its inhibitor TIMP1 (43) and could thus promote fibrosis reversal. Here, we have shown that peripheral $\mathrm{CB}_{1} \mathrm{R}$ blockade by MRI-1867 can engage all three of the above mechanisms, most likely by reversing the fibrosis-related increase in hepatic endocannabinoid "tone," which is reflected in the increased hepatic $\mathrm{CB}_{1} \mathrm{R}$ expression as well as hepatic endocannabinoid levels in the fibrotic liver (Figure 6E).

As for the secondary target iNOS, its activation as a proinflammatory mechanism contributing to fibrosis progression has been well documented, as detailed in the Introduction. In addition, iNOS protein and enzyme activity are markedly elevated in the livers of patients with cirrhosis caused by viral hepatitis, alcohol abuse, and cholestasis (50). There are also reports supporting an opposite, antifibrotic role of NO and iNOS in liver fibrosis induced by thioacetamide (51) or prolonged high-fat diet (52). However, other findings indicate that NO involved in fibrosis resolution and the related improvement in hepatic circulation may be generated via eNOS, which, in contrast to iNOS, is downregulated in fibrosis $(53,54)$. The present observations are in agreement with the majority of findings supporting the profibrotic function of iNOS (53-56) and the antifibrotic effect of iNOS inhibition $(56,57)$. This is evident in the markedly reduced levels of BDL-induced fibrosis in the livers of nos $2^{-1-}$ mice (Figure 4), which are also known to be less sensitive to $\mathrm{CCl}_{4}$-induced cirrhosis compared with wild-type mice (15). The antifibrotic efficacy of the iNOS inhibitor $1400 \mathrm{~W}$ in BDL-induced fibrosis (Figure 8) further supports the profibrotic function of iNOS. The contribution of iNOS inhibition to the antifibrotic efficacy of MRI-1867 is clearly indicated by its antifibrotic activity in $c n r 1^{-1-}$ mice and by the loss of its differential efficacy relative to rimonabant in nos $2^{-1-}$ mice (Figure 4).

The greater antifibrotic efficacy of MRI-1867 compared with rimonabant suggests that iNOS inhibition selectively blunts profibrotic signaling in the liver that is unaffected by $\mathrm{CB}_{1} \mathrm{R}$ blockade. Unique iNOS targets have been defined as being inhibited by MRI-1867 in wild-type and $c n r 1^{-1-}$ mice but not in nos $2^{-1-}$ mice. One such target is the PDGF/PDGFR $\beta$ pathway and its downstream mediator endosialin (CD248), which promote the proliferation and transdifferentiation of quiescent stellate cells into profibrotic myofibroblasts (58). MRI-1867 may inhibit this pathway by blocking iNOS-mediated NO production in hepatocytes, thus preventing a possible paracrine effect of NO on neighboring stellate cells. Activation of TGF- $\beta$, the other major growth factor pathway involved in stellate cell activation is suppressed by $\mathrm{CB}_{1} \mathrm{R}$ blockade, but iNOS inhibition also targets TGF- $\beta$ via blocking the expression of $\alpha v \beta 6$ integrin, a cell adhesion molecule expressed in proliferating bile duct epithelial cells that binds latent TGF- $\beta$ to release active TGF- $\beta(31,59)$. $\alpha$ v $\beta 6$ Integrin is also expressed in hepatic progenitor cells, in which it promotes their differentiation into cholangiocytes and hepatocytes, whereas inactivation of $\alpha \mathrm{v} \beta 6$ promotes hepatic fibrosis and cholangiopathy models (60). 
Thus, iNOS inhibition may mitigate fibrosis not only via antiinflammatory mechanisms, but also by inhibiting the regenerative capacity of the liver. On the other hand, the greater antifibrotic activity of MRI-1867 compared with $1400 \mathrm{~W}$ (Figure 8 ) may reflect mechanisms uniquely targeted by $\mathrm{CB}_{1} \mathrm{R}$ blockade, such as the increased tissue levels of anandamide and the increased expression of $\mathrm{CB}_{1} \mathrm{R}$ in the fibrotic liver.

$\mathrm{CB}_{1} \mathrm{R}$ is expressed by multiple cell types in the liver, including hepatocytes (61), stellate cells (11), and infiltrating macrophages (6), and iNOS is also known to be expressed in hepatocytes (50) as well as hepatic macrophages (14). Further studies are needed to explore the relative contribution of different types of liver cells as targets of the antifibrotic effect of combined inhibition of $\mathrm{CB}_{1} \mathrm{R}$ and iNOS.

Interestingly, in wild-type mice with either BDL-induced or $\mathrm{CCl}_{4}$-induced liver fibrosis, rimonabant moderately reduced iNOS gene and protein expression (Figure 5 and Figure 8). An explanation of this may involve recent findings that fibrosis progression is driven by the infiltration of the liver with proinflammatory macrophages expressing the N1rp3 inflammasome (62) and that activation of $\mathrm{CB}_{1} \mathrm{R}$ on such macrophages promotes their transmigration and proinflammatory activity, whereas $\mathrm{CB}_{1} \mathrm{R}$ blockade produces opposite effects (6) and also suppresses the expression of NF- $\kappa B$ (63), a transcription factor promoting nos2 gene expression (64). In contrast to rimonabant, MRI-1867 completely reversed the increase in iNOS activity, most likely due to the enzyme inhibitory action of the acetamidine leaving group. The parallel inhibition of nos 2 gene expression is similar to findings with other iNOS inhibitors (57) and likely reflects the blockade of a positive feedback loop, whereby peroxynitrite generated via iNOS leads to the upregulation of NF- $\mathrm{BB}$ and, consequently, nos2. Thus, inhibition of iNOS by the acetamidine leaving group may well contribute to the exceptionally high antifibrotic efficacy of the dual-target $\mathrm{CB}_{1} \mathrm{R} / \mathrm{iNOS}$ inhibitor.

The dual targeting of peripheral $\mathrm{CB}_{1} \mathrm{R}$ and iNOS demonstrated here exemplifies the therapeutic gain obtained by simultaneously hitting more than one molecule, which could then engage distinct as well as convergent cellular pathways. The advantage of such an approach is highlighted by emerging experience with recently developed antifibrotic medications, which indicates that targeting a single pathway has limited effect on fibrotic diseases (34). Thus, the approach illustrated by the present study has promise as an effective antifibrotic strategy.

\section{Methods}

Additional details are provided in the Supplemental Methods .

Chemistry. The chemical synthesis, purification and verification of the structure of MRI-1867 are described in the Supplemental Methods.

Materials. Rimonabant and CP-55,940 were obtained from the National Institute of Drug Abuse Drug Supply Program (Research Triangle Park, North Carolina, USA). Arachidonoyl-2'-chloroethylamine (ACEA) and Fumonisin B were from Cayman. $\left[{ }^{2} \mathrm{H}_{4}\right]$ AEA was synthesized by the reaction of arachidonoyl chloride with $\left[{ }^{2} \mathrm{H}_{4}\right]$ ethanolamine (65). $\left[{ }^{3} \mathrm{H}\right] \mathrm{CP} 55,940,\left[{ }^{35} \mathrm{~S}\right] \mathrm{GTP} \gamma \mathrm{S},\left[{ }^{3} \mathrm{H}\right]$ arginine, and $\left[{ }^{14} \mathrm{C}(\mathrm{U})\right]$ arginine were from Perkin-Elmer. All other chemicals were from Sigma-Aldrich.

Animals. Male 8- to 10-week-old C57BL/6J mice were obtained from The Jackson Laboratory. Mice were maintained under a 12-hour-light/12-hour-dark cycle and fed ad libitum. To induce liver fibrosis, 10 - to 12 -week-old mice were subjected either to $\mathrm{BDL}$ surgery or $\mathrm{CCl}_{4}$ treatment as indicated. To generate diet-induced obesity, C57BL/6J mice were fed a high-fat diet (D12492, Research Diets Inc., 60\% of calories as fat). Lean controls were mice kept on a standard laboratory diet (NIH-31 rodent diet) for 14 weeks.

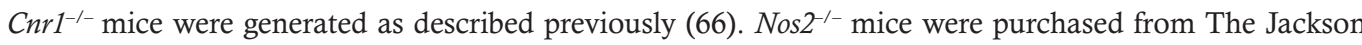
Laboratory. Cnr1 ${ }^{-/-}$, nos2 ${ }^{-/-}$, and $m d r 1 a^{-/-}$mice were on C57B1/6J genetic background.

Induction of liver fibrosis by $\mathrm{CCl}_{4}$. Hepatocellular liver fibrosis was generated by i.p. injection of $\mathrm{CCl}_{4}(1$ $\mathrm{ml} / \mathrm{kg}$, diluted 1:10 corn oil) twice weekly. Animals were sacrificed 40 hour after the last $\mathrm{CCl}_{4}$ dose.

Induction of liver fibrosis by BDL. Ligation of the common bile duct was performed as described previously (67). Average survival was 18-20 days after the surgery. Therefore the study was completed at 14 days after surgery, at which time severe fibrosis was evident with low interindividual variability.

Drug treatment. The compounds were administered by oral gavage daily in both acute and chronic studies as indicated.

Blood chemistry. Blood was collected at the time the mice were sacrificed. Serum ALT and AST were quantified using AMS Vegasys Chemistry Analyzer (Diamond Diagnostics). Blood glucose was determined using the Elite glucometer (Bayer). 
Hepatic triglyceride content. Liver tissue was extracted as described previously (33), and its triglyceride content was determined using the EnzyChrom Triglyceride Assay kit (BioAssay Systems).

Glucose tolerance and insulin sensitivity tests. The assays were performed (13) following 1 week of daily oral doses of MRI-1867, as described. i.p. glucose tolerance tests were performed after overnight fasting by i.p. administration of glucose at $1.5 \mathrm{mg} / \mathrm{kg}$ and subsequent sampling of tail blood at 15 -minute intervals. i.p. insulin sensitivity tests were performed on the next day after a 6-hour fast by treating mice with a bolus dose of insulin $(0.75 \mathrm{U} / \mathrm{kg})$. Blood glucose levels were measured from tail blood.

$C B_{I} R$-binding assays. The assay was performed as described previously (68). Briefly, binding affinity of the compounds to $\mathrm{CB}_{1} \mathrm{R}$ and $\mathrm{CB}_{2} \mathrm{R}$ was determined by radioligand displacement assays using 1 and 0.6 $\mathrm{nM}$ of $\left[{ }^{3} \mathrm{H}\right] \mathrm{CP} 55,940$ as the radioligand, respectively. Plasma membranes were prepared from mouse and rat brain or from cultured $\mathrm{CHO}-\mathrm{K} 1$ cells stably transfected with human $\mathrm{CB}_{1} \mathrm{R}$ or $\mathrm{CB}_{2} \mathrm{R}$ (Perkin Elmer). Twenty microgram or four microgram plasma membrane protein was used in a 1-ml reaction mixture for rodent and human sources, respectively. $\mathrm{K}_{\mathrm{i}}$ values were derived by computerized curve fitting and using the Cheng-Prusoff equation to account for the affinity of the radioligand, using the GraphPad Prism 6 program (GraphPad Prism Software Inc.).

${ }^{35} S J G T P \gamma$ S-binding assay. The assay was performed as described previously (68). Inverse agonism by MRI-1867 and rimonabant was determined in the absence of agonist, whereas their potency as antagonists $\left(\mathrm{IC}_{50}\right)$ was determined in the presence of the agonist CP55,940 (300 nM), which generated a CB $\mathrm{R}$-mediated increase in GTP $\gamma \mathrm{S}$ binding at the $\sim \mathrm{EC}_{80}$ level. Ten $\mu$ g plasma membrane protein was used in a $1.0-\mathrm{ml}$ reaction mixture.

Upper GI motility assay. The assay was performed as described previously (68). To determine inverse agonism, MRI-1867 or rimonabant was administered orally by gavage to male 8 - to 10 -week-old mice 1 hour prior to an oral bolus of $10 \%$ charcoal suspension in $5 \%$ gum arabic. Thirty minutes later, the mice were killed, and the distance traveled by the head of the marker between the pylorus and the cecum was measured and expressed as percentage of total length of the small intestine. To assess in vivo $\mathrm{CB}_{1} \mathrm{R}$ antagonism, MRI-1867 or rimonabant was administered 30 minutes after an oral dose of the $\mathrm{CB}_{1} \mathrm{R}$ agonist ACEA $(5 \mathrm{mg} / \mathrm{kg})$, with the rest of the procedure as described above.

Hyperambulatory activity. The assay was performed as described previously (68). Locomotor activity of drug-naive mice treated with an oral bolus dose of $\mathrm{CB}_{1} \mathrm{R}$ antagonist or vehicle was quantified by the number of disruptions of infrared beams in 2 dimensions in an activity chamber. The drugs were administered 3 hour after the start of the light cycle.

Elevated plus-maze test. Anxiety-related behavior was assessed using the elevated plus-maze test as described previously (33). Mice were tested 1 hour after either acute or 28-day chronic oral administration of rimonabant or MRI-1867.

Real-time PCR analyses. RNA extraction was performed using RNeasy Mini Kits (Qiagen). One microgram of total RNA was reverse transcribed to cDNA using SuperScript II (Invitrogen). Expression of the target gene was quantified with gene-specific primers and PowerSYBR Green master mix (ABI) using a 7500 Real-Time PCR instrument (Applied Biosystems). Predesigned mouse Rpl19, tgfb1, acta2, timp1, nos2, and cnr1 primers were purchased from Qiagen. Gene expression values were calculated based on the $\Delta \Delta \mathrm{Ct}$ method.

PET. In vivo $\mathrm{CNS} \mathrm{CB}_{1} \mathrm{R}$ occupancy by MRI-1867 and rimonabant was assessed by their ability to displace the $\mathrm{CB}_{1} \mathrm{R}$ PET radiotracer $\left[{ }^{18} \mathrm{~F}\right] \mathrm{FMPEP}-d 2$, as described previously (12). The specific activity of the $\mathrm{PET}$ radiotracer at the time of injection was $927 \pm 212 \mathrm{mCi} / \mu \mathrm{mol}$ (mean $\pm \mathrm{SD}$ ). Lean control mice $(26 \pm$ $3 \mathrm{~g}$ ) were treated orally with MRI-1867 $(3,10$, and $30 \mathrm{mg} / \mathrm{kg})$, rimonabant $(3 \mathrm{mg} / \mathrm{kg})$, or vehicle 1 hour prior to radioligand injection. Concurrent to injection of $127 \pm 29 \mu \mathrm{Ci}$ of $\left[{ }^{18} \mathrm{~F}\right] \mathrm{FMPEP}-d 2$, PET scans began and continued for 120 minutes on a Siemens microPET Focus 120 camera (Siemens Medical Solutions). Images were reconstructed without attenuation and scatter correction. For each animal, a brain time activity curve was constructed and activity was expressed as a standardized uptake value, which compensates for the injected activity and body weight. Whole brain uptake was determined by area under the time activity curve from 60 to 120 minutes after radioligand injection.

Endocannabinoid measurements. The tissue levels of endocannabinoids were measured by stable isotope dilution liquid chromatography/tandem mass spectrometry (LC-MS/MS) as described previously (69).

Nonspecific protein binding in brain. Nonspecific binding of MRI-1867 to brain tissue was determined by equilibrium dialysis as described previously (12) using crude brain membrane preparations from $\mathrm{CB}_{1} \mathrm{R}^{-/}$ 
mice. The membranes were incubated with $2 \mu \mathrm{M}$ MRI-1867 in D-tube dialyzer maxi dialysis apparatus (Novagen). The levels of free (unbound) MRI-1867 were determined by LC-MS/MS.

Tissue levels of drugs. Tissues and plasma were extracted as described previously (69), and MRI-1867 levels were determined by LC-MS/MS using an Agilent 6410 triple quadrupole mass spectrometer (Agilent Technologies) coupled to an Agilent 1200 LC system (Agilent Technologies). Chromatographic and mass spectrometer conditions were set as described previously (70). Levels of each compound were analyzed by multiple reactions monitoring. The molecular ion and fragments for each compound were measured as follows: $m / z 548.1 \rightarrow 145$ and $548.1 \rightarrow 257.1$ for MRI-1867 (CID energy: $56 \mathrm{~V}$ and $24 \mathrm{~V}$, respectively), $m / z$ $59.1 \rightarrow 42.1$ and $59.1 \rightarrow 44.1$ for acetamidine (CID energy: $1 \mathrm{~V}$ and $2 \mathrm{~V}$, respectively), and $\mathrm{m} / z 524 \rightarrow 105$ and $524 \rightarrow 506.3$ for a hydroxylated urea metabolite (CID energy: $16 \mathrm{~V}$ and $0 \mathrm{~V}$, respectively). The amounts of MRI-1867 in the samples were determined against standard curves. Values are expressed as ng/g or ng/ml in wet tissue weight or plasma volume, respectively.

Metabolism of MRI-1867 by liver microsomes. MRI-1867 ( $3 \mu \mathrm{M})$ was incubated with mouse liver microsomes (GIBCO, ThermoFisher Scientific, $2 \mathrm{mg}$ protein/aliquot) at $37^{\circ} \mathrm{C}$ for 90 minutes in $200 \mu 1$ reaction buffer (100 mM KH $\mathrm{PO}_{4}, 4 \mathrm{mM}$ NADPH, 3 mM MgCl 2 , pH 7.4). Controls containing no MRI-1867 were used to establish baseline ion chromatogram. The reaction was stopped by addition of $200 \mu \mathrm{l}$ of ice-cold methanol and incubation for at least 20 minutes at $-20^{\circ} \mathrm{C}$. The samples were centrifuged at $13,000 \mathrm{~g}$ for 10 minutes, and the supernatants were analyzed by LC-MS/MS to detect acetamidine.

Fluorimetric iNOS assay. Fluorimetric Cell-Associated Nitric Oxide Synthase Detection System (Sigma-Aldrich) was used for measuring iNOS activity in RAW 264.7 cells (ATCC) as per the supplier's instructions. Cells were preincubated with LPS $(50 \mathrm{ng} / \mathrm{ml})$ and $\gamma$-interferon $(10 \mathrm{ng} / \mathrm{ml})$ for 24 hours to induce iNOS activity before adding the test compounds for an additional hour, with 100,000 cells/well used per reaction.

Radioisotopic hepatic iNOS activity assay. Hepatic iNOS activity was measured by the rate of conversion of $\left[{ }^{14} \mathrm{C}(\mathrm{U})\right] \mathrm{L}$-arginine to $\left[{ }^{14} \mathrm{C}(\mathrm{U})\right] \mathrm{L}$-citrulline by using a NOS activity assay kit (Cayman). The assay was performed as previously described (50) with modifications to yield specific iNOS activity. Briefly, liver samples (25 mg wet weight) were homogenized by Precellys homogenizer in $5 \times$ volume of ice-cold homogenization buffer containing $50 \mathrm{mM}$ Tris HCL, $320 \mathrm{mM}$ sucrose, $1 \mathrm{mM}$ DTT, and protease inhibitors (AEBSF $1 \mathrm{mM}$, aprotinin $0.8 \mu \mathrm{M}$, bestatin $50 \mu \mathrm{M}$, E-64 $15 \mu \mathrm{M}$, leupeptin $20 \mu \mathrm{M}$, pepstatin A $15 \mu \mathrm{M}$ ), followed by centrifugation at $10,000 \mathrm{~g}$ for 20 minutes at $4^{\circ} \mathrm{C}$. The supernatant was centrifuged at $100,000 \mathrm{~g}$ for 1 hour at $4^{\circ} \mathrm{C}$ to purify the iNOS-containing soluble compartment. Five $\mu$ of the supernatant was incubated at $37^{\circ} \mathrm{C}$ for 3 minutes in assay buffer with supplementation of L-arginine $(20 \mu \mathrm{M})$, L-citrulline $(1 \mathrm{mM})$, norvaline $(10 \mathrm{mM})$, and fumonisin $\mathrm{B}(300 \mu \mathrm{M})$. In the liver, L-arginine and L-citrulline are utilized by urea cycle enzymes and are also substrates for arginase and argininosuccinate synthase, respectively. In order to prevent the breakdown of $\left[{ }^{14} \mathrm{C}(\mathrm{U})\right] \mathrm{L}$-arginine and $\left[{ }^{14} \mathrm{C}(\mathrm{U})\right] \mathrm{L}$-citrulline by urea cycle enzymes and arginase, the argininosuccinate synthase inhibitor fumonisin $\mathrm{B}$ and the arginase inhibitor norvaline were added to the reaction mixture. The specificity of the iNOS activity measured was further confirmed by its inhibition by $1 \mathrm{mM} \mathrm{N}$-nitro-L-arginine (L-NNA). Enzyme activity was expressed as percentage conversion of $\left[{ }^{14} \mathrm{C}\right]$ L-arginine to $\left[{ }^{14} \mathrm{C}\right] \mathrm{L}$-citrulline.

Radioisotopic eNOS activity assay. eNOS activities were measured by the rate of conversion of $\left[{ }^{3} \mathrm{H}\right]$ L-arginine to [ $\left.{ }^{3} \mathrm{H}\right] \mathrm{L}$-citrulline by using a NOS activity assay kit (Cayman), as per the supplier's instructions. This assay was used to measure the effects of the test substances on eNOS activity, using recombinant bovine eNOS (Cayman).

3-Nitrotyrosine tissue levels. 3-Nitrotyrosine levels in liver tissue, as an indicator of protein nitrosylation by iNOS, were determined using an ELISA kit from MyBiosource.com (MBS005184).

Hyp measurement by LC-MS/MS. For this method, $50 \mathrm{mg}$ liver tissue was homogenized in $500 \mu 1$ of ice-cold $0.1 \mathrm{~N}$ perchloric acid (PCA) to which $500 \mu 12 \mathrm{~N} \mathrm{HCL}$ was added and the homogenate was hydrolyzed at $100^{\circ} \mathrm{C}$ for 4 hours. Hydrolyzed samples were vortexed and centrifuged at $10,000 \mathrm{~g}$ for 10 minutes, and $10 \mu 1$ hydrolysate was diluted 20 -fold by the addition of $190 \mu 1$ of $0.1 \mathrm{~N}$ PCA. LC-MS/ MS analyses were conducted on an Agilent 6410 triple quadrupole mass spectrometer (Agilent Technologies) coupled to an Agilent 1200 LC system. 4-Hyp was separated using an Intrada Amino Acid column, $50 \times 3 \mathrm{~mm}, 3 \mu \mathrm{m}$ (Imtakt) at $40^{\circ} \mathrm{C}$. Mobile phases consisted of acetonitrile/tetrahydrofu$\mathrm{ran} / 25 \mathrm{mM}$ ammonium formate/formic acid = 9:75:16:0.3 (v/v/v/v) (phase A) and acetonitrile/100 $\mathrm{mM}$ ammonium formate $=20: 80(\mathrm{v} / \mathrm{v})($ phase B). Gradient elution $(600 \mu 1 / \mathrm{min})$ was initiated and held at $0 \%$ B for 3 minutes, followed by a linear increase to $17 \%$ B by 6.5 minutes. This was followed by a 
step increase to $100 \% \mathrm{~B}$, which was held until 10 minutes after the gradient was begun, and then by a linear decrease to $0 \%$ B by 11 minutes, which was held until 13 minutes after the gradient was begun. The mass spectrometer was set for electrospray ionization operated in positive ion mode. The source parameters were as follows: capillary voltage, $4,000 \mathrm{~V}$; gas temperature, $330^{\circ} \mathrm{C}$; and drying gas, $81 / \mathrm{min}$. Nitrogen was used as the nebulizing gas. Collision-induced dissociation (CID) was conducted using nitrogen. Hyp level was analyzed by multiple reaction monitoring. The molecular ion and fragments for Hyp were measured as follows: $m / z 132.1 \rightarrow 86$ and $132.1 \rightarrow 68$ (CID energy: $8 \mathrm{~V}$ and $20 \mathrm{~V}$, respectively). Hepatic levels of Hyp were determined against a standard curve, using trans-4-hydroxy-L-proline as standard (Sigma-Aldrich). Values are expressed as nmol/mg wet tissue.

Picrosirius red staining. To visualize fibrotic areas, liver tissue was fixed in $10 \%$ neutralized formalin solution and embedded in paraffin. Tissues were cut at $4-\mu \mathrm{m}$ thickness for staining, and staining was performed as described previously (67).

Tunel staining. Tunel staining was performed using the TUNEL Apoptosis Detection Kit (Millipore Corp.). Sections were then counterstained with hematoxylin, Gill's formula (Vector Labs), and analyzed using an Olympus BX41 microscope.

Histology and immunohistochemistry. Liver tissues were fixed in $10 \%$ neutralized formalin solution, embedded in paraffin, and sectioned $(4 \mu \mathrm{m})$ onto glass slides. Section were stained with antibody against iNOS (Abcam 15323), NLRP3 (Novus Biochemical, NBP2-12446), and CD68 (Abcam 31630) and developed using ABC-elite-HRP/diaminobenzidine system (Vector Labs), counterstained with hematoxylin, Gills Formula (Vector Labs), and analyzed using an Olympus BX41 microscope.

Histology data analysis. Images were taken from at least 8 randomly selected areas from of each liver section. Collagen deposition in liver tissues was quantified by measuring Sirius red-stained areas using ImageJ software (NIH) by a person blind to the sample ID. Quantification of images from one sample was averaged for actual data presentation for each sample ( $n=6-12$ animals/group).

Histological assessment of ductular proliferation. The degree of ductular proliferation was assessed in H\&E-stained sections. The number of ductular profiles was counted in 50 portal areas from each liver, and their average number per portal area was determined.

Statistics. Values shown are expressed as mean \pm SEM. Statistical analysis was performed by unpaired 2-tailed Student's $t$ test or by 1 -way ANOVA, as appropriate. $P<0.05$ was considered significant.

Study approval. Animal experiments and protocols were approved by the Institutional Animal Care and Use Committee of the National Institute on Alcohol Abuse and Alcoholism, NIH.

\section{Author contributions}

RC planned and performed in vivo and in vitro experiments, analyzed data, and participated in manuscript preparation. MRI designed, synthesized, and chemically analyzed MRI-1867. ZC and KE performed BDL surgeries. TJ, RC, ZL, JKP, and BM performed histology and immunohistochemistry and prepared images. GG performed behavioral experiments. GS and TJ contributed to in vivo experiments. JL performed cell-based experiments. ZL performed PCR and RT-PCR. AZR analyzed and interpreted histological data. RGL provided $m d r 1 \alpha^{-1-}$ mice. PP participated in manuscript preparation. J-SL and RBI performed and analyzed $\mathrm{CB}_{1} \mathrm{R}$ PET experiments. RC and $\mathrm{GK}$ designed the study, interpreted data, and wrote the manuscript.

\section{Acknowledgments}

This work was supported by intramural funds from the National Institute on Alcohol Abuse and Alcoholism to GK, the National Institute of Mental Health to RBI, and the National Institute of Drug Abuse to MRI. We thank Kenner Rice for helpful comments and Bill Leister for use of their LC-MS and Noel Whittaker for mass spectrometry data on MRI-1867. We thank Judy Harvey-White for technical assistance with mass spectrometry experiments.

Address correspondence to: Resat Cinar, Laboratory of Physiologic Studies (LPS), National Institute on Alcohol Abuse and Alcoholism, NIH, 5625 Fishers Lane, Room 2S-18, Rockville, Maryland 20852, USA. Phone: 301.443.4098; E-mail: resat.cinar@nih.gov. Or George Kunos, Scientific Director, National Institute on Alcohol Abuse and Alcoholism, NIH, 5625 Fishers Lane, MSC-9413, Bethesda, Maryland 208929413, USA. Phone: 301.443.2069; E-mail: george.kunos@nih.gov. 
1. Lee YA, Wallace MC, Friedman SL. Pathobiology of liver fibrosis: a translational success story. Gut. 2015;64(5):830-841.

2. Bolognesi ML. Polypharmacology in a single drug: multitarget drugs. Curr Med Chem. 2013;20(13):1639-1645.

3. Ghiassi-Nejad Z, Friedman SL. Advances in antifibrotic therapy. Expert Rev Gastroenterol Hepatol. 2008;2(6):803-816.

4. Pacher P, Kunos G. Modulating the endocannabinoid system in human health and disease--successes and failures. FEBS J. 2013;280(9):1918-1943.

5. Silvestri C, Di Marzo V. The endocannabinoid system in energy homeostasis and the etiopathology of metabolic disorders. Cell Metab. 2013;17(4):475-490.

6. Jourdan T, et al. Activation of the Nlrp3 inflammasome in infiltrating macrophages by endocannabinoids mediates beta cell loss in type 2 diabetes. Nat Med. 2013;19(9):1132-1140.

7. Jeong WI, et al. Paracrine activation of hepatic CB1 receptors by stellate cell-derived endocannabinoids mediates alcoholic fatty liver. Cell Metab. 2008;7(3):227-235.

8. Hézode C, et al. Daily cannabis smoking as a risk factor for progression of fibrosis in chronic hepatitis C. Hepatology. 2005;42(1):63-71.

9. Ravinet Trillou C, et al. Anti-obesity effect of SR141716, a CB1 receptor antagonist, in diet-induced obese mice. Am J Physiol Regul Integr Comp Physiol. 2003;284(2):R345-R353.

10. Després JP, Golay A, Sjöström L, Rimonabant in Obesity-Lipids Study Group. Effects of rimonabant on metabolic risk factors in overweight patients with dyslipidemia. N Engl J Med. 2005;353(20):2121-2134.

11. Teixeira-Clerc F, et al. CB1 cannabinoid receptor antagonism: a new strategy for the treatment of liver fibrosis. Nat Med. 2006;12(6):671-676.

12. Tam J, et al. Peripheral cannabinoid-1 receptor inverse agonism reduces obesity by reversing leptin resistance. Cell Metab. 2012;16(2):167-179.

13. Cinar R, et al. Hepatic cannabinoid-1 receptors mediate diet-induced insulin resistance by increasing de novo synthesis of longchain ceramides. Hepatology. 2014;59(1):143-153.

14. Karlmark KR, et al. Hepatic recruitment of the inflammatory Gr1+ monocyte subset upon liver injury promotes hepatic fibrosis. Hepatology. 2009;50(1):261-274.

15. Aram G, Potter JJ, Liu X, Torbenson MS, Mezey E. Lack of inducible nitric oxide synthase leads to increased hepatic apoptosis and decreased fibrosis in mice after chronic carbon tetrachloride administration. Hepatology. 2008;47(6):2051-2058

16. López-Sánchez LM, Corrales FJ, Barcos M, Espejo I, Muñoz-Castañeda JR, Rodríguez-Ariza A. Inhibition of nitric oxide synthesis during induced cholestasis ameliorates hepatocellular injury by facilitating S-nitrosothiol homeostasis. Lab Invest. 2010;90(1):116-127.

17. Tang Y, et al. Nitric oxide-mediated intestinal injury is required for alcohol-induced gut leakiness and liver damage. Alcohol Clin Exp Res. 2009;33(7):1220-1230.

18. Hazam RK, Deka M, Kar P. Role of nitric oxide synthase genes in hepatitis E virus infection. J Viral Hepat. 2014;21(9):671-679

19. Navarro LA, et al. Arginase 2 deficiency results in spontaneous steatohepatitis: a novel link between innate immune activation and hepatic de novo lipogenesis. J Hepatol. 2015;62(2):412-420.

20. Perreault M, Marette A. Targeted disruption of inducible nitric oxide synthase protects against obesity-linked insulin resistance in muscle. Nat Med. 2001;7(10):1138-1143.

21. Yang L, et al. METABOLISM. S-Nitrosylation links obesity-associated inflammation to endoplasmic reticulum dysfunction. Science. 2015;349(6247):500-506.

22. Hellio le Graverand MP, et al. A 2-year randomised, double-blind, placebo-controlled, multicentre study of oral selective iNOS inhibitor, cindunistat (SD-6010), in patients with symptomatic osteoarthritis of the knee. Ann Rheum Dis. 2013;72(2):187-195.

23. Need AB, et al. The relationship of in vivo central CB1 receptor occupancy to changes in cortical monoamine release and feeding elicited by CB1 receptor antagonists in rats. Psychopharmacology (Berl). 2006;184(1):26-35.

24. Young RJ, et al. Inhibition of inducible nitric oxide synthase by acetamidine derivatives of hetero-substituted lysine and homolysine. Bioorg Med Chem Lett. 2000;10(6):597-600.

25. Hirvonen J, et al. Reversible and regionally selective downregulation of brain cannabinoid CB1 receptors in chronic daily cannabis smokers. Mol Psychiatry. 2012;17(6):642-649.

26. Aviello G, Romano B, Izzo AA. Cannabinoids and gastrointestinal motility: animal and human studies. Eur Rev Med Pharmacol Sci. 2008;12 Supp1 1:81-93.

27. Weiler-Normann C, Herkel J, Lohse AW. Mouse models of liver fibrosis. Z Gastroenterol. 2007;45(1):43-50.

28. Jourdan T, Djaouti L, Demizieux L, Gresti J, Vergès B, Degrace P. CB1 antagonism exerts specific molecular effects on visceral and subcutaneous fat and reverses liver steatosis in diet-induced obese mice. Diabetes. 2010;59(4):926-934.

29. Cao S, et al. Neuropilin-1 promotes cirrhosis of the rodent and human liver by enhancing PDGF/TGF-beta signaling in hepatic stellate cells. J Clin Invest. 2010;120(7):2379-2394.

30. Wilhelm A, et al. CD248/endosialin critically regulates hepatic stellate cell proliferation during chronic liver injury via a PDGF-regulated mechanism. Gut. 2016;65(7):1175-1185.

31. Wang B, et al. Role of alphavbeta6 integrin in acute biliary fibrosis. Hepatology. 2007;46(5):1404-1412.

32. Wree A, et al. NLRP3 inflammasome activation results in hepatocyte pyroptosis, liver inflammation, and fibrosis in mice. Hepatology. 2014;59(3):898-910.

33. Tam J, et al. Peripheral CB1 cannabinoid receptor blockade improves cardiometabolic risk in mouse models of obesity. J Clin Invest. 2010;120(8):2953-2966.

34. Nanthakumar CB, Hatley RJ, Lemma S, Gauldie J, Marshall RP, Macdonald SJ. Dissecting fibrosis: therapeutic insights from the small-molecule toolbox. Nat Rev Drug Discov. 2015;14(10):693-720.

35. Wree A, Broderick L, Canbay A, Hoffman HM, Feldstein AE. From NAFLD to NASH to cirrhosis-new insights into disease mechanisms. Nat Rev Gastroenterol Hepatol. 2013;10(11):627-636. 
36. Tam J, Liu J, Mukhopadhyay B, Cinar R, Godlewski G, Kunos G. Endocannabinoids in liver disease. Hepatology. 2011;53(1):346-355.

37. Després JP, Ross R, Boka G, Alméras N, Lemieux I, ADAGIO-Lipids Investigators. Effect of rimonabant on the high-triglyceride/ low-HDL-cholesterol dyslipidemia, intraabdominal adiposity, and liver fat: the ADAGIO-Lipids trial. Arterioscler Thromb Vasc Biol. 2009;29(3):416-423.

38. van der Poorten D, et al. Hepatitis C virus induces the cannabinoid receptor 1. PLoS ONE. 2010;5(9)(9).

39. Shahidi M, et al. Endocannabinoid CB1 antagonists inhibit hepatitis $\mathrm{C}$ virus production, providing a novel class of antiviral host-targeting agents. J Gen Virol. 2014;95(Pt 11):2468-2479.

40. Mukhopadhyay B, et al. Cannabinoid receptor 1 promotes hepatocellular carcinoma initiation and progression through multiple mechanisms. Hepatology. 2015;61(5):1615-1626.

41. Wallace MC, Friedman SL. Hepatic fibrosis and the microenvironment: fertile soil for hepatocellular carcinoma development Gene Expr. 2014;16(2):77-84.

42. Björnson E, et al. Stratification of hepatocellular carcinoma patients based on acetate utilization. Cell Rep. 2015;13(9):20142026.

43. Giannone FA, et al. Reversal of liver fibrosis by the antagonism of endocannabinoid CB1 receptor in a rat model of CCl(4)-in duced advanced cirrhosis. Lab Invest. 2012;92(3):384-395.

44. Patsenker E, et al. Cannabinoid receptor type I modulates alcohol-induced liver fibrosis. Mol Med. 2011;17(11-12):1285-1294.

45. DeLeve LD, Wang X, Kanel GC, Atkinson RD, McCuskey RS. Prevention of hepatic fibrosis in a murine model of metabolic syndrome with nonalcoholic steatohepatitis. Am J Pathol. 2008;173(4):993-1001.

46. Wei Y, Kang XL, Wang X. The peripheral cannabinoid receptor 1 antagonist VD60 efficiently inhibits carbon tetrachloride-in toxicated hepatic fibrosis progression. Exp Biol Med (Maywood). 2014;239(2):183-192.

47. Trebicka J, et al. Role of cannabinoid receptors in alcoholic hepatic injury: steatosis and fibrogenesis are increased in CB2 receptor-deficient mice and decreased in CB1 receptor knockouts. Liver Int. 2011;31(6):860-870.

48. Chen SW, et al. Suppression of CB1 cannabinoid receptor by lentivirus mediated small interfering RNA ameliorates hepatic fibrosis in rats. PLOS ONE. 2012;7(12):e50850.

49. Mahmoud MF, Swefy SE, Hasan RA, Ibrahim A. Role of cannabinoid receptors in hepatic fibrosis and apoptosis associated with bile duct ligation in rats. Eur J Pharmacol. 2014;742:118-124.

50. McNaughton L, et al. Distribution of nitric oxide synthase in normal and cirrhotic human liver. Proc Natl Acad Sci USA. 2002;99(26):17161-17166

51. Lukivskaya O, Patsenker E, Lis R, Buko VU. Inhibition of inducible nitric oxide synthase activity prevents liver recovery in rat thioacetamide-induced fibrosis reversal. Eur J Clin Invest. 2008;38(5):317-325.

52. Nozaki Y, et al. Deficiency of iNOS-derived NO accelerates lipid accumulation-independent liver fibrosis in non-alcoholic steatohepatitis mouse model. BMC Gastroenterol. 2015;15:42.

53. Leung TM, Tipoe GL, Liong EC, Lau TY, Fung ML, Nanji AA. Endothelial nitric oxide synthase is a critical factor in experimental liver fibrosis. Int J Exp Pathol. 2008;89(4):241-250.

54. Wang W, Zhao C, Zhou J, Zhen Z, Wang Y, Shen C. Simvastatin ameliorates liver fibrosis via mediating nitric oxide synthase in rats with non-alcoholic steatohepatitis-related liver fibrosis. PLoS ONE. 2013;8(10):e76538.

55. Leung TM, Fung ML, Liong EC, Lau TY, Nanji AA, Tipoe GL. Role of nitric oxide in the regulation of fibrogenic factors in experimental liver fibrosis in mice. Histol Histopathol. 2011;26(2):201-211.

56. Anavi S, Eisenberg-Bord M, Hahn-Obercyger M, Genin O, Pines M, Tirosh O. The role of iNOS in cholesterol-induced liver fibrosis. Lab Invest. 2015;95(8):914-924.

57. Kikuchi H, et al. New strategy for the antifibrotic therapy with oral administration of FR260330 (a selective inducible nitric oxide synthase inhibitor) in rat experimental liver cirrhosis. Wound Repair Regen. 2007;15(6):881-888.

58. Pellicoro A, Ramachandran P, Iredale JP, Fallowfield JA. Liver fibrosis and repair: immune regulation of wound healing in a solid organ. Nat Rev Immunol. 2014;14(3):181-194.

59. Patsenker E, Popov Y, Stickel F, Jonczyk A, Goodman SL, Schuppan D. Inhibition of integrin alphavbeta6 on cholangiocytes blocks transforming growth factor-beta activation and retards biliary fibrosis progression. Gastroenterology. 2008;135(2):660-670

60. Peng ZW, et al. Integrin $\alpha v \beta 6$ critically regulates hepatic progenitor cell function and promotes ductular reaction, fibrosis, and tumorigenesis. Hepatology. 2016;63(1):217-232.

61. Osei-Hyiaman D, et al. Endocannabinoid activation at hepatic CB1 receptors stimulates fatty acid synthesis and contributes to diet-induced obesity. J Clin Invest. 2005;115(5):1298-1305

62. Wree A, et al. NLRP3 inflammasome activation is required for fibrosis development in NAFLD. J Mol Med. 2014;92(10):1069-1082

63. Malfitano AM, Laezza C, Pisanti S, Gazzerro P, Bifulco M. Rimonabant (SR141716) exerts anti-proliferative and immunomodulatory effects in human peripheral blood mononuclear cells. Br J Pharmacol. 2008;153(5):1003-1010.

64. Lowenstein CJ, et al. Macrophage nitric oxide synthase gene: two upstream regions mediate induction by interferon gamma and lipopolysaccharide. Proc Natl Acad Sci USA. 1993;90(20):9730-9734.

65. Giuffrida A, Rodríguez de Fonseca F, Piomelli D. Quantification of bioactive acylethanolamides in rat plasma by electrospray mass spectrometry. Anal Biochem. 2000;280(1):87-93.

66. Zimmer A, Zimmer AM, Hohmann AG, Herkenham M, Bonner TI. Increased mortality, hypoactivity, and hypoalgesia in cannabinoid CB1 receptor knockout mice. Proc Natl Acad Sci USA. 1999;96(10):5780-5785.

67. Mukhopadhyay P, et al. Poly (ADP-ribose) polymerase-1 is a key mediator of liver inflammation and fibrosis. Hepatology. 2014;59(5):1998-2009.

68. Iyer MR, et al. Structural basis of species-dependent differential affinity of 6-alkoxy-5-aryl-3-pyridinecarboxamide cannabinoid-1 receptor antagonists. Mol Pharmacol. 2015;88(2):238-244.

69. Mukhopadhyay B, et al. Hyperactivation of anandamide synthesis and regulation of cell-cycle progression via cannabinoid type 1 (CB1) receptors in the regenerating liver. Proc Natl Acad Sci USA. 2011;108(15):6323-6328.

70. Godlewski G, et al. Inhibitor of fatty acid amide hydrolase normalizes cardiovascular function in hypertension without adverse metabolic effects. Chem Biol. 2010;17(11):1256-1266. 